\title{
Photosynthesis at the forefront of a sustainable life
}

\section{Paul J. D. Janssen ${ }^{1}$, Maya D. Lambreva ${ }^{2}$, Nicolas Plumeré ${ }^{3}$, Cecilia Bartolucci ${ }^{2}$, Amina Antonacci ${ }^{2}$, Katia Buonasera ${ }^{2}$, Raoul N. Frese ${ }^{4}$, Viviana Scognamiglio ${ }^{2}$ and Giuseppina Rea ${ }^{2 *}$}

\author{
${ }^{1}$ Molecular and Cellular Biology - Unit of Microbiology, Institute for Environment, Health and Safety, Belgian Nuclear Research Centre SCK•CEN, Mol, Belgium \\ 2 Institute of Crystallography, National Research Council of Italy, Rome, Italy \\ ${ }^{3}$ Center for Electrochemical Sciences-CES, Ruhr-Universität Bochum, Bochum, Germany \\ ${ }^{4}$ Division of Physics and Astronomy, Department of Biophysics, VU University Amsterdam, Amsterdam, Netherlands
}

\section{Edited by:}

Om Parkash Dhankher, University of Massachusetts Amherst, USA

Reviewed by:

Amarendra Narayan Misra, Central University of Jharkhand, India Elizabeth Lucy Rylott, University of York, UK

Bibin Paulose, University of

Massachusetts Amherst, USA

*Correspondence:

Giuseppina Rea, Institute of

Crystallography, National Research

Council of Italy, Via Salaria Km

29,300, Rome 00015, Italy

e-mail: giuseppina.rea@ic.cnr.it
The development of a sustainable bio-based economy has drawn much attention in recent years, and research to find smart solutions to the many inherent challenges has intensified. In nature, perhaps the best example of an authentic sustainable system is oxygenic photosynthesis. The biochemistry of this intricate process is empowered by solar radiation influx and performed by hierarchically organized complexes composed by photoreceptors, inorganic catalysts, and enzymes which define specific niches for optimizing light-to-energy conversion. The success of this process relies on its capability to exploit the almost inexhaustible reservoirs of sunlight, water, and carbon dioxide to transform photonic energy into chemical energy such as stored in adenosine triphosphate. Oxygenic photosynthesis is responsible for most of the oxygen, fossil fuels, and biomass on our planet. So, even after a few billion years of evolution, this process unceasingly supports life on earth, and probably soon also in outer-space, and inspires the development of enabling technologies for a sustainable global economy and ecosystem. The following review covers some of the major milestones reached in photosynthesis research, each reflecting lasting routes of innovation in agriculture, environmental protection, and clean energy production.

Keywords: photosynthesis, photosynthetic yield improvement, bioremediation, biofuels, biosensors, artificial photosynthesis, sustainability, space agriculture

\section{INTRODUCTION}

Sustainability has been described by the European Union as follows: "Strictly speaking sustainability implies the use of resources at rates that do not exceed the capacity of the Earth to replace them." (http://ec.europa.eu/environment/eussd/food. htm). Sustainability however does not come about by its own but requires dynamic and responsible actions to create and maintain a balance between society, environment, and economy. In the next 10-20 years, a steady increase of the global population, continuous competition for land, water, and energy, and the worsening effects brought by climate change will be the three foremost science policy-determining factors. Innovations in agriculture no doubt will have a great impact on sustainability since they would address the usage and purification of water, the availability of good-quality soil, the supply of energy including "green" energy, the importance of biodiversity, and above all, the command and safety of food and feed. It is mandatory however that this is done in an interdisciplinary way following a holistic approach.

Photosynthesis is one of the most efficiently cycled and sustainable processes we know in Nature. This deceivingly simple process forms the basis for all the energy sources essential to life, from the intake of food to the burning of fossil fuels, and more recently, for the industrial production of value-added chemicals or bio-energy. Green plants, algae and cyanobacteria are able to oxidise water for photosynthesis and hence are oxygenic, in contrast to other phototrophs that use different electron donors, such as hydrogen sulfide. The splitting of water $\left(\mathrm{H}_{2} \mathrm{O}\right)$ giving off oxygen gas $\left(\mathrm{O}_{2}\right)$ is a complex event, requiring the absorption of solar energy by a set of aligned chlorophyll $(\mathrm{Chl})$ pigments that as a result release electrons to convert $\mathrm{CO}_{2}$ to carbohydrates, a reaction known as carbon fixation. The full process can be summarised in a single equation:

$$
\mathrm{H}_{2} \mathrm{O}+\mathrm{CO}_{2}+\text { light } \rightarrow \mathrm{C}\left(\mathrm{H}_{2} \mathrm{O}\right)+\mathrm{O}_{2}
$$

Oxygenic photosynthesis evolved approximately 2.5 billion years ago, the core reactions, light harvesting, charge separation, water splitting, and energy storage remaining similar across species. However, natural optimization of the mechanism through a series of fine physical and biochemical modifications allowed adaptation of the process to specific ecological niches. For instance, the evolution of $\mathrm{C} 3$ into $\mathrm{C} 4$ pathways enabled plants to attain, under certain conditions, an efficiency increase of their photosynthetic processes of up to $50 \%$.

This review reports on research inspired by photosynthesis, addressing global, environmental and societal issues related to crops improvement, eco-system homeostasis maintenance and clean energy production, with the aim to identify opportunities and challenges for sustainable innovation and development. 


\section{PHOTOSYNTHESIS AT THE FOREFRONT OF A SECURE FOOD SUPPLY}

The global demand of nutrition largely depends on photosynthesis efficiency. Presently achieved crop yields however lay far below the projected needs required to meet the predicted population growth, threatening global food security (Fedoroff et al., 2010; Long, 2014). Current photosynthesis research is much inspired by the call for a sustainable agriculture and the tuning of food, feed, and energy production in respect to each other (Nair, 2014). The main challenge however lays in increasing crop yields without encumbering land and water resources nor by burdening the environment with an excess of herbicides or nitrogen-rich manure. Analyses of current knowledge and outputs of biochemical and microclimatic photosynthetic models indicate that, by exploiting variations of existing germplasms and by engineering photosynthesis (Zhu et al., 2010a; Reynolds et al., 2011; Gu et al., 2014), sustainable yield increases of crops could be achieved. The present section encompasses recent advances to increase the radiation-use efficiency (RUE) of crops, hence production yields, by overcoming natural photosynthetic limits and improving light perception.

\section{OVERCOMING THE MAIN LIMITS OF C3 PHOTOSYNTHESIS}

Plant growth and biomass production rely on carbohydrate synthesis within the Calvin-Benson cycle, which is initiated by the incorporation of $\mathrm{CO}_{2}$ into ribulose 1,5-bisphosphate ( $\mathrm{RuBP}$ ) by ribulose 1,5-bisphosphate carboxylase/oxygenase ( $\mathrm{RuBisCO}$ ). Eukaryotic RuBisCO comprises eight large (LS, chloroplastencoded; containing the active sites) and eight small (SS, nuclearencoded) subunits, organized in $\mathrm{L}_{8} \mathrm{~S}_{8}$ macromolecules (Whitney et al., 2011a). RuBisCO catalysis requires pre-activation via an ancillary enzyme, RuBisCO activase (RA). It involves a complex 5-step reaction, and is further complicated by electrostatic similarity between $\mathrm{CO}_{2}$ and $\mathrm{O}_{2}$, as well as regular enzyme inhibition and -reactivation (Andersson and Backlund, 2008). RuBisCO promptly reacts with $\mathrm{O}_{2}$, losing approximately $25 \%$ of previously fixed $\mathrm{CO}_{2}$ through the photorespiratory pathway. RuBisCO's dual function and its low carboxylation rate $\left(V_{c}\right)$ compromise its efficiency and are among the main factors determining the low RUE of C3 plants (Zhu et al., 2010b). Manipulation of RuBisCO's catalytic traits, modulation of its inhibition, or RA optimization were recognized as main targets in the struggle for the increase of crops yields (Raines, 2011; Whitney et al., 2011a; Parry et al., 2013; Mueller-Cajar et al., 2014). In addition, improving C3 RuBisCO catalytic turnover should diminish the required RuBisCO amount (normally representing approximately 50 and $25 \%$ of leaf protein and nitrogen content, respectively) increasing nitrogen use efficiency of crops.

Comparative analyses of natural RuBisCO variants demonstrated that an increase in the carboxylation rate is generally obtained at the expense of $\mathrm{CO}_{2}$ affinity $\left(K_{m}\right)$ and/or specificity $\left(S_{C / O}\right)$. The high $V_{c}$ of $\mathrm{C} 4$ type RuBisCO, coupled to low $\mathrm{CO}_{2}$ specificity/affinity, requires restriction of the enzyme's access to atmospheric oxygen for best results. A more intriguing target is a variant $\mathrm{RuBisCO}$ which evolved in some red algae and possesses high $S_{C / O}$, keeping $V_{c}$ values similar to those in the C3 plants (Whitney et al., 2011a). Another promising approach is a detailed structural, biogenetic and catalytic characterization of RuBisCO forms developed under challenging growth conditions (Miller et al., 2013). The production of chimeric $\mathrm{L}_{8} \mathrm{~S}_{8}$ complexes or manipulation of LS and SS is hindered by the complex RuBisCO biogenesis and spatial separation of the LS- and SS-encoding genes in the chloroplast and nucleus, respectively (Whitney et al., 2011a; Parry et al., 2013). However, a better understanding of RuBisCO folding and assembly (Liu et al., 2010; Kolesinski et al., 2013) has enabled the engineering of LS peptides with improved catalytic properties in Chlamydomonas reinhardtii (Zhu et al., 2010a; Maliga and Bock, 2011) and tobacco plants (Whitney et al., 2009, 2011b) resulting in increased photosynthetic rates and higher biomass. Furthermore, RuBisCO-mediated carbon fixation with C4-like catalysis (high $V_{c}$ and high $K_{m}$ ) was realized in rice by introducing SS from sorghum and eliciting functional chimeric $\mathrm{L}_{8} \mathrm{~S}_{8}$ complexes (Genkov et al., 2010; Ishikawa et al., 2011).

Due to the natural behavior of RuBisCO enzyme to form stable intermediate complexes with sugar phosphates, its $V_{c}$ declines with time and repeated interventions of RA are required to prevent the so-called enzyme fallover (Mueller-Cajar et al., 2014). Attempts have been made to reduce RuBisCO fallover by lowering its sensitivity to the specific by-products or by accelerating the transformation of RuBisCO inhibitors into less active metabolites (Parry et al., 2013). Phosphate-induced impediment of RuBisCO heightens with the increase in temperature and highlights the main flaw of RA: its low thermostability. It was demonstrated that expanding the temperature range of RA stability (via overexpression of RA from warm- into cool-season species) or improving RA thermostability (via replacing the endogenous RA by a more thermostable enzyme) can give cause to increased photosynthetic performances and yields under moderate heat stress (Kumar et al., 2009; Carmo-Silva and Salvucci, 2012).

Metabolic control analyses indicated that the RuBisCO carboxylation reaction is the controlling step in the efficacy of the Calvin-Benson cycle, particularly under high light, high temperature and low $\mathrm{CO}_{2}$ conditions (Zhu et al., 2010b; Raines, 2011). Investigations using antisense RNA silencing to reduce RuBisCO protein levels revealed additional enzymes able to control the C3-cycle efficiency by modulating the RuBP regeneration rate (Raines, 2011). However, the mechanisms that regulate carboxylation-cycle reactions must be fully understood in order to introduce appropriate modifications. It was shown that the increase in photosynthetic rate and concomitant gain in biomass owing to the overexpression of sedoheptulose-1,7-bisphosphatase in fact is highly species- and growth dependent and that the overexpression of transketolase actually affects plant growth negatively, probably due to changes in the $\mathrm{C} 3$-cycle carbon exchange balance (Raines, 2011).

Parallel to the efforts to engineer RuBisCO proteins with increased $V_{c}$, extensive research focused on increasing C3cycle productivity by bypassing the photorespiratory pathway. Photorespiration entails the sequential transformation of phosphoglycolate (PG), the RuBP oxygenation product, back into glycerate to join the Calvin-Benson cycle in the chloroplast via a series of peroxisome- and mitochondrion-located reactions (Peterhansel et al., 2010). The regeneration of oxygenated RuBP 
consumes reducing equivalents and energy, and is associated with the release of $\mathrm{CO}_{2}$ and ammonia derived from previously fixed carbon and nitrogen (Peterhansel et al., 2013). Three different approaches to circumvent this "wasteful" lane have been proposed and tested in plants with different successes (Figure 1): (i) catabolization of PG to RuBP and $\mathrm{CO}_{2}$ in chloroplasts (Kebeish et al., 2007) (Bypas 1), (ii) a similar reaction in peroxisomes (Carvalho et al., 2011) (Bypass 2), and (iii) oxidization of PG to $\mathrm{CO}_{2}$ and pyruvate in chloroplasts (Maier et al., 2012) (Bypass 3). Bypasses 1 and 3 proved to be functional in Arabidopsis plants, and resulted in enhanced photosynthesis and growth. Both pathways are energetically less costly than the photorespiratory route, possibly avoiding ammonia re-fixation and releasing $\mathrm{CO}_{2}$ in chloroplasts (Peterhansel et al., 2010; Maier et al., 2012; Peterhansel et al., 2013). The integration of these basic approaches into agriculturally significant crops is still a challenge and the translation of their benefits into crop yields needs to be determined.

Some green algae and cyanobacteria are useful as feedstock and are regarded as safe for human consumption. Such microalgae generally perform $\mathrm{C} 3$ photosynthesis and rely on bicarbonate and $\mathrm{CO}_{2}$ transport. A carbon concentration mechanism (CMM) in green algae consists of a spatial regulation of carbonic anhydrase activity and the low- $\mathrm{CO}_{2}$ induced formation of a starch sheet around the pyrenoid, a proteinaceous structure where most
(>90\%) of the RuBisCo becomes encapsulated. In cyanobacteria a similar CCM exists, but here bicarbonates are transferred from the cytoplasm to a separate compartment, the carboxysome, which is not permeable by oxygen. Herein, a carbonic anhydrase converts bicarbonate to $\mathrm{CO}_{2}$ used as enriched substrate by the carboxysome-enclosed RuBisCo. It has been recently suggested that C3 plant photosynthesis might be improved through the introduction of microalgal bicarbonate pumps (Price et al., 2013) or complete carboxysomes (Zarzycki et al., 2013) or pyrenoids (Meyer and Griffiths, 2013) into their chloroplasts but these potential routes have not yet been demonstrated.

\section{ENGINEERING C4 PHOTOSYNTHESIS IN C3 CROPS}

Today, although only $3 \%$ of all vascular plants exhibit C4photosynthesis, they account for one-fifth of the global primary productivity owing to ample high-yield C4-grass-lands. In general, C4 plants (i.e., maize, sugar cane, sorghum) are more efficient at photosynthesis than C3 plants and fix carbon at higher rates, use less water per weight of biomass produced, and tolerate to a better extent water and high temperature stress. But, in terms of ground use and taking into account that only parts of plants are edible, C3 crops (e.g., potato, soybean) produce some of the highest edible calories and protein per square meter. $\mathrm{C} 4$ photosynthesis is characterized by a two-step carbon fixation for the establishment of a $\mathrm{CO}_{2}$-enriched RuBisCO environment and

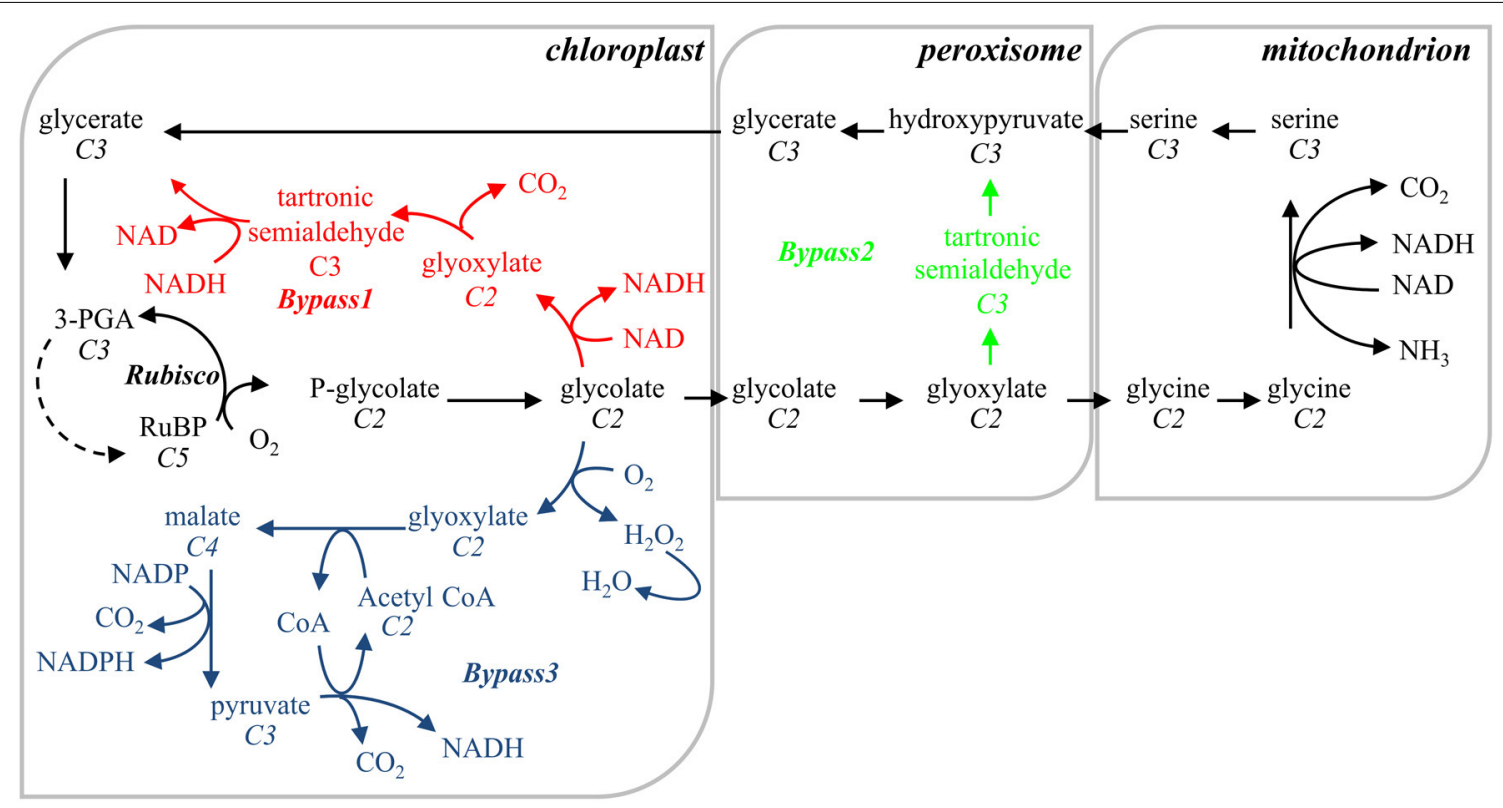

FIGURE 1 | Schematic representation of the photorespiratory pathway (in black) and the three circumvent pathways designed to overcome the photorespiratory losses. The reactions of bypass 1 (in red) are entirely realized into the chloroplast and comprise the transformation of glycolate to glycerate, introducing glycolate dehydrogenase, glycine decarboxylase and tartronate semialdehyde reductase similar to the $E$. coli glycolate catabolic pathway (Kebeish et al., 2007). Bypass 2 (in green) follows the E. coli glyoxylate catabolic pathway in the peroxisomes by introducing glycine decarboxylase and hydroxypyruvate isomerase (Carvalho et al., 2011). Bypass 3 (in blue) oxidizes glycolate to $\mathrm{CO}_{2}$ in the chloroplast, using exogenous (glycolate oxidase and catalase from the peroxisomes, and malate synthase from the glyoxysomes) and endogenous (malic enzyme and pyruvate dehydrogenase) enzymes (Maier et al., 2012). In all three bypasses release of ammonia in the mitochondrion is abolished; $75 \%$ of the glycolate redirected toward bypasses 1 and 2 is returned to the Calvin-Benson cycle as 3-PGA; bypasses 1 and 3 dislocate $\mathrm{CO}_{2}$ released from the mitochondrion to the chloroplast. Reactions stoichiometry is not taken into account; the numbers of carbon atoms of each metabolic compound are in italic; 3-PGA, 3-phosphoglycerate; RuBP, ribulose 1,5-bisphosphate. 
creates conditions in which photorespiration is negligible. The majority of $\mathrm{C} 4$ species have higher RUE and biomass production than the C3 types, particularly in warm habitats (Langdale, 2011). These benefits are especially evident in species which evolved CCM, spatially separating the carbon fixation and carboxylation between the chloroplasts of mesophyll cells (MCs) and bundle sheath cells (BSCs), also known as Kranz anatomy or the Kranztype $\mathrm{C} 4$ cycle. In contrast to $\mathrm{C} 3$, both $\mathrm{C} 4$ cell types are rich in chloroplast: $\mathrm{MC}$ chloroplasts possess a granal-stromal lamellae organization and lack the enzymes involved in the Calvin-Benson and photorespiration pathways; BSCs show predominantly stromal lamellae and a typical C3 enzymatic profile. C4 metabolism invests in enlarged and photosynthetically active BSCs, a high number of veins, a heavy metabolite traffic, and the functional coordination between BSCs and MCs. The introduction of a C4 cycle into typical C3 species, such as rice and soybean, is predicted to increase crop yield, with concomitant improvement in water and nitrogen-use efficiency (Zhu et al., 2010b; Langdale, 2011; Wang et al., 2011). The difficult transfer of high-yield C4 metabolism in important $\mathrm{C} 3$ crops, such as rice, became one of the main goals of the international C4 Rice Consortium (http:// c4rice.irri.org/) established less than 10 years ago and aiming to address the growing food demand (von Caemmerer et al., 2012). The production of rice with acquired functional C4-biochemistry requires modification and integration of numerous biochemical pathways and adequate adaptation of rice leaf anatomy. The main approaches undertaken for the realization of this ambitious project have been thoroughly described (Kajala et al., 2011; Langdale, 2011; Leegood, 2013; Karki et al., 2013) and include: (i) the integration in rice of genes typical for the C4 metabolism, reaching expression levels conferring high photosynthetic yields, such as the genes encoding phosphoenolpyruvate carboxylase in MCs and enzymes from Calvin-Benson cycle in BSCs, (ii) the down-regulation of endogenous rice genes, e.g., encoding MC enzymes of the Calvin-Benson cycle and photorespiration, (iii) the introduction of $\mathrm{C} 4$ cell-type specific gene expression and protein accumulation in rice, including identification of suitable regulatory elements to ensure the protein's compartmentalization between MCs and BSCs, and (iv) the identification of C4 transporters carrying out the metabolite transfer between the subcellular compartments and the introduction of the corresponding genes into the rice genome. Significant progress was made through the identification of gene promoters for compartmental gene expression (Wang et al., 2013a), gene cloning for the main enzymes of the C4 metabolic pathway from maize and their transformation into rice (Kajala et al., 2011), and the determination of candidate transporters of intermediate metabolites between MCs and BSCs (Karki et al., 2013).

Another important challenge is altering rice leaf anatomy and morphology in order to make it comparable with the Kranztype biochemistry. The BSCs of rice, a typical C3 plant, contain too few chloroplasts to attain high-yield C4 photosynthesis (Karki et al., 2013). This hurdle can be bypassed by cell-type specific overexpression of genes implicated in chloroplast development, thylakoid stacking, and photosystems assembly such as the homologous gene pair of the Golden2-like (GLK1, GLK2) transcription factors (Langdale, 2011; Karki et al., 2013). The confirmation of a differential accumulation of GLKs in maize MCs and BSCs and their regulatory role in dimorphic chloroplast differentiation (Wang et al., 2013b) proved this approach to be correct. Even more encouraging was the successful introduction of Kranz anatomy trails in C3 leaves, which caused an increase in vein density and larger BSC cells in an oat-maize chromosome addition (OMA) line (i.e., Avena sativa plants containing a maize chromosome) (Tolley et al., 2012). A large interaction surface and closed contact between MC and BSC are mandatory requirements for fulfilling the needs of the heavily loaded intercellular metabolite exchange typical for the $\mathrm{C} 4$ cycle. Recently, the first gene (scarecrow) responsible for the $\mathrm{C} 4$ specific leaf patterning could be identified (Slewinski et al., 2012; Wang et al., 2013a) while a better knowledge of Kranz-type leaf structure development and the underlying evolutionary mechanisms will be instrumental to engineer high-yield photosynthesis in rice (Slewinski, 2013).

\section{IMPROVING CANOPY PHOTOSYNTHETIC PERFORMANCE}

Improvements of the photosynthetic efficiency on chloroplast/leaf level can lead to an increase of crop yield if the engineered traits can be effectively introduced on plant canopy level. In this context, the main concern is the unequal light distribution within the plant canopy, resulting in an excessive light overload at canopy surface and severe light limitation within the lower canopy levels (Zhu et al., 2010b, 2012). Improving the efficiency in which crops are able to convert intercepted light into biomass requires the identification of an ideal canopy architecture (thus optimizing canopy performance) while keeping in mind the species- and habitat-specific requirements. A possible approach is the breeding or engineering of plants with more erected leaves and dwarf phenotypes causing a better canopy light distribution and conversion while reducing stem investment and lodging losses. Mathematical models can estimate quite accurately the canopy distribution of the light-limited and lightsaturated photosynthesis in different species and environmental conditions, thus assisting the identification of improved crop specific architecture (Zhu et al., 2012; Song et al., 2013). To this end, considerable progress was made in unraveling the genetic basis of plant architecture (Jin et al., 2008; Wang and Li, 2008; Zheng and Liu, 2013).

Additional tactics to improve canopy RUE have also been explored. One of the most commonly used approaches is the reduction of leaf chlorophyll content, i.e., by light-harvesting antenna complex (LHC) size reduction, to effectively diminish excess light caught by upper-canopy leaves. The superfluous absorbed light causes a photoinhibitory inactivation of the photosynthetic reactions and is largely dissipated through nonphotochemical quenching mechanism. In addition, this approach would cause an increase in light availability in the lower-canopy levels, relieving their light-limited photosynthesis (Zhu et al., 2010b; Ort et al., 2011). Furthermore, increased canopy light penetration could also positively alter the heat canopy balance by lowering the temperature in the upper portion and increasing it near to the soil, thus improving crop yield (Ort et al., 2011).

The adjustment of chlorophyll content and composition as well as truncation of light-capturing antenna has been successfully applied for an improvement of RUE and an increase in 
biomass yield for microalgal mass cultures. Among the different strategies to accomplish this, silencing or down-regulation of LHC encoding genes proved to be effective, leading to a higher cell culture density, less fluorescence quenching and a better photosynthetic quantum yield, while algal cultures were more tolerant to oversaturating light intensities (Kirst et al., 2012; Gimpel et al., 2013). In contrast, Synechocystis sp. PCC 6803 mutants with truncated phycobilisome antenna showed reduced growth rate and whole-culture biomass production (Page et al., 2012; Liberton et al., 2013). For crops, the benefits of LCH size reduction in terms of season-long carbon gains have yet to be rigorously tested (Ort et al., 2011). Other lines of interest are the discovery of the hitherto unknown chlorophyll $f$ displaying a red-shifted absorption maximum (Chen et al., 2010) and the reconsideration of the photosynthetic potential of chlorophyll $d$ (Mielke et al., 2013). These findings propounded the idea to improve plant RUE by extending the by plants usable spectrum of photosynthetically active radiation, or PAR (Chen and Blankenship, 2011; Blankenship and Chen, 2013). Besides the development of all these strategies to boost high photosynthetic yields, the possibility to improve photoprotection capacity in crops should be kept in mind as well (Murchie and Niyogi, 2011).

\section{BIOREMEDIATION AND BIOMONITORING BASED ON PHOTOSYNTHESIZERS}

Synthetic fertilizers and agrochemicals play a major role to meet the ever increasing global demand for food. However, the excessive and improper use of these chemicals has turned agriculture into a major source for environmental pollution. A fine example is the use of nitrogen-rich fertilizers which, while allowing for a tremendous increase in crop productivity, resulted in nitrate and nitrite run-offs that have heavily disturbed many lake and river ecosystems. In addition, the ammonium required for fertilizer production is industrially made via the Haber process utilizing up to $5 \%$ of the global natural gas production. Thus, the current use of such fertilizers translates in massive $\mathrm{CO}_{2}$ emissions arising from the nitrogen extraction, the transport of raw materials and products, as well as the actual fertilizer production.

Adjusting fertilizer input to avoid excessive runoffs and preserve fossil gas resources have become priorities for modern farming practices. In particular, the development of field sensing methods, such as deployed for nitrate (Plumeré et al., 2012a,b; Plumeré, 2013), may allow farmers to better estimate the fertilizer needs of crops. In parallel, remediation of contaminated water, soil, and atmosphere has become exigent. Commonly used nitrate removal methods include chemical precipitation, ion exchange, electrodialysis, and reverse osmosis. While these strategies may be applied to clean up contaminated water, they are impractical for in situ use, come at an additional energy cost, and cause further $\mathrm{CO}_{2}$ emissions. Instead, solar light driven microbial processes are applicable in situ and carry a greater promise for environment-friendly bioremediation.

The general term bioremediation refers to a number of waste management techniques involving the use of plants or microbes (bacteria, yeasts, fungi, algae) to eliminate or reduce the concentration of pollutants from a contaminated site (reviewed by Bhatnagar and Kumari, 2013; Willscher et al., 2013). Lately, the term phytoremediation has been adopted for the specific use of plants, while the term phycoremediation is now specifically applied to the use of (green) algae or cyanobacteria. Phytoremediation may consist of one or more of six different phytotechnologies (phytotransformation, rhizofiltration, phytostabilization, phytovolatilization, evapotranspiration, and phytoextraction) depending on the used plant and the type and depth of contamination (Paz-Alberto and Sigua, 2013; Moosavi and Seghatoleslami, 2013). Phycoremediation equally benefits from the use of oxygenic photosynthesis but the use of microalgae and cyanobacteria offers some advantages including a higher biomass productivity, a much faster growth, an easier control of cellular response, the avoidance of arable land use, and the ability to extract micro- and macronutrients from wastewaters or industrial flue gasses (Anemaet et al., 2010; McGinn et al., 2011; Pittman, 2011). Plants, microalgae, and cyanobacteria have been studied extensively in recent years as effective accumulators, biosorbents, and degraders useful for the bioremediation of different kinds of organic and inorganic pollutants (Olguín, 2003; Gosh and Singh, 2005; Mehta and Gaur, 2005; Marmiroli et al., 2006; Lone et al., 2008; Chinnasamy et al., 2010; Kong et al., 2010; Wang et al., 2010; De Philippis et al., 2011; Moosavi and Seghatoleslami, 2013; Paz-Alberto and Sigua, 2013).

Coupling the growth of microalgae on wastewater with energy production has been proposed since the 60's (Oswald and Golueke, 1960; Benemann et al., 1977; Hoffmann, 1998; Mallick, 2002; Rawat et al., 2011; Olguín, 2012; Fahti et al., 2013) while the efficiency of sustainable low-cost wastewater treatment based on microalgae has been confirmed in the past decade (de-Bashan and Bashan, 2010). In spite of these promising developments, several challenges and limitations exist for microalgal biomass in terms of aeration and adequate quantities of light (taking into account self-shading and turbidity in ponds or reservoirs, but also photoinhibition), fluctuations in temperature and $\mathrm{pH}$, harvesting and extraction costs, and down-stream processing (Scott et al., 2010; Hannon et al., 2011; McGinn et al., 2011; Rawat et al., 2012). Yield and cost analyses for algal systems versus traditional fuel crops indicate that algal systems are not yet cost-effective (van Bellen, 2009; Beal et al., 2012; Slade and Bauen, 2013) and life cycle assessments (LCAs) such as recently reported by Passell et al. (2013) using commercial data for algal production of biodiesel are clearly wanted (see also section Evaluation of Environmental and Social Impacts of Biomass Energy production). Nonetheless, microalgal, and cyanobacterial systems that combine bioremediation (i.e., waste water treatment) or $\mathrm{CO}_{2}$ mitigation with the production of potentially valuable biomass - whether biofuels or other added-value products-remain attractive novel routes. In particular when (bio)technological advances, including genetic modifications, could improve their cost-effectiveness and enhance their role in global endeavors for a sustainable life. Hence, in the next sections of this review we mainly focus on microalgal bioremediation and biofuels.

\section{MICROALGAE FOR BIOREMEDIATION Phosphorus and Nitrogen removal}

Nitrogen and phosphorus are serious pollutants accumulating in waters as a result of agricultural runoff. The major effect 
of releasing wastewater rich in organic and inorganic chemicals such as nitrates and phosphates is mainly eutrophication (Correll, 1998), with consequent hypoxia or anoxia of aquatic animals. Microalgae, in this context, can offer an attractive solution as they are able to grow in wastewater conditions by utilizing the abundant organic carbon and inorganic nitrogen and phosphorus (Pittman, 2011) thus acting as bioremediators against these elements.

Phosphorus. Phosphorus is an essential element for all life forms. Autotrophs can assimilate this mineral nutrient only as an orthophosphate, i.e., after hydrolysis of its organic forms by extracellular enzymes. The presence of this element in soils is often limited owing to the formation of insoluble complexes. In general, water-soluble phosphate used in fertilizer suffuses, while less than $20 \%$ is absorbed by plants (Vance et al., 2003). Phosphate enters ground water, streams and rivers, and moves out to sea and oceans where it is directly consumed by marine phytoplankton thus entering the food chain (Baturin, 2003). Since microalgae accumulate phosphorus as polyphosphate bodies stored inside the acidocalcisome organelle (Seufferheld and Curzi, 2010), these photosynthetic organisms can be doubly useful: as bioremediators, to remove the excess of phosphorus from waters, and as temporary storage, to capture this macronutrient and return it to the terrestrial environment in form of agricultural fertilizer (Sivakumar et al., 2012).

Nitrogen. Plants, microbes and algae absorb nitrogen from soil or water and store it as biomass. Over time, the biomass decomposes releasing nitrogen into the soil (e.g., as ammonia, urea) or into the atmosphere (e.g., as $\mathrm{N}_{2} \mathrm{O}$ ), where it may be recycled or lost. Although $\mathrm{N}_{2} \mathrm{O}$ is not produced in significant amounts in the presence of nitrates, it is not known if other nitrogenous compounds found in wastewater, such as urea and ammonia, are converted to this greenhouse gas. Since microalgae have unique natural mechanisms for removing excess of nitrogen, phosphorus and $\mathrm{CO}_{2}$ from water sources, these organisms have been widely investigated for nitrogen removal. C. vulgaris was used for nitrogen and phosphorus removal from wastewater with an average removal efficiency of $72 \%$ for nitrogen and $28 \%$ for phosphorus (Aslan and Kapdan, 2006), while other microalgae widely used for nutrient removal were Chlorella (Lee and Lee, 2001), Scenedesmus (Martínez et al., 2000), and Spirulina species (Olguín et al., 2003), next to Nannochloris (Jimenez-Perez et al., 2004) and Botryococcus braunii (An et al., 2003).

\section{$\mathrm{CO}_{2}$ capturing}

Microalgae have the ability to fix $\mathrm{CO}_{2}$ (generally via the BensonCalvin cycle) with an efficiency 10-50 times higher than that of terrestrial plants ( $\mathrm{Li}$ et al., 2008). Through the photosynthetic process, microalgae can completely recycle $\mathrm{CO}_{2}$, producing the chemical energy necessary for the completion of their vital functions. For this reason, $\mathrm{CO}_{2}$ mitigation by microalgae is still considered the best strategy for an efficient removal of this greenhouse gas and to address global warming, especially when combined with algal biofuel production (Wang et al., 2008).

Light intensity, temperature, and $\mathrm{CO}_{2}$ concentration strongly affect $\mathrm{CO}_{2}$ fixation, in the way that increasing light intensity while maintaining moderate temperature and moderate solute concentration, increases both fixation and $\mathrm{CO}_{2}$ solubility in liquids (Atkinson and Mavituna, 1991). One of the best sources of highly enriched $\mathrm{CO}_{2}$ is flue gas containing $10-20 \% \mathrm{CO}_{2}$ from burning fossil fuels ( $\mathrm{Ge}$ et al., 2011), but algal species differ in their apparent ability to use $\mathrm{CO}_{2}$ effectively. High level of $\mathrm{CO}_{2}$ inhibit some species, while others can thrive on $\mathrm{CO}_{2}$ levels up to $20 \%$ (certain strains of Chlorella, Scenedesmus, and Cyanidium even grow in $40-100 \% \mathrm{CO}_{2}$-reviewed by Salih, 2011). The efficient mass transfer of $\mathrm{CO}_{2}$ to cells in the aqueous environment of large-scale liquid culture systems is therefore challenging. Nonetheless, efficient capture of $\mathrm{CO}_{2}, \mathrm{NO}$, and $\mathrm{SO}_{2}$ for algal biomass production by directly introducing flue gas into microalgal cultures have been reported (Chiu et al., 2011 and reviewed by Van Den Hende et al., 2012).

\section{Heavy metals}

Heavy metals are known to cause, in human beings, various physiological disorders to hepatic, renal, respiratory, and gastrointestinal systems. The toxicity of heavy metals depends on their concentration, bioavailability, and chemical forms, and the duration of exposure. The ever-increasing contamination of aquatic bodies and soils by heavy metals is an issue of serious concern and challenge world-wide. Bioremediation of heavy metalcontaminated water employing various microorganisms, including microalgae, has been recognized as a cheaper, more effective and an eco-friendly alternative to the conventional physicochemical remediation methods. Considerable research effort has been therefore devoted to the development of algal biosorbents able to remediate these pollutants (Hazrat et al., 2013).

Biosorption of metal ions from aquatic complex matrices is based on the interaction of metal ions with the functional groups on the surface or within the cellular wall of the algae biomass. This phenomenon clearly depends on the typical binding profile of the biosorbent. Therefore, different algal species having different sizes, shapes, and cell wall compositions will have different metal binding efficiencies (Monteiro et al., 2011).

Current methods used to treat heavy metal wastewater include chemical precipitation, ion-exchange, adsorption, membrane filtration, coagulation-flocculation, flotation and electrochemical methods, even if only the first three techniques are the most frequently studied, as recently reviewed by Fu and Wang (2011) and Vandamme et al. (2013).

Cyanobacteria that produce extracellular polysaccharides (EPS) have been successfully applied for the removal of a wide range of metals from water, including $\mathrm{Co}, \mathrm{Cu}, \mathrm{Cr}, \mathrm{Pb}$, and $\mathrm{Zn}$ (reviewed by De Philippis et al., 2011) and extracted biomasses of cyanobacteria have been used to adsorb radionuclides of Cs, Sr, Ra, and Am (Pohl and Schimmack, 2006). An interesting application of green microalgae (Hydrodictyon sp., Oedogonium sp., and Rhizoclonium sp.) for the bioremediation of heavy metals such as As and Cd, is described by Saunders et al. (2012), who reported an alternative and practical approach to algal bioremediation of metals in which algae are cultured directly in the waste water stream. Other green algae, i.e. Closterium moniliferum and Coccomyxa actinabiotis, which show efficient and selective radionuclide sequestration and are extremely radioresistant, are 
prime candidates for in situ biodecontamination in the nuclear industry (Krejci et al., 2011; Rivasseau et al., 2013). In the aftermath of the Fukushima nuclear accident the search for additional cyanobacteria and algae, but also aquatic plants, that can be deployed to efficiently eliminate radionuclides from the environment, has intensified (Fukuda et al., 2014). Another interesting study describes a system dynamics approach to explore the efficacy of using mixed microalgae populations to treat leachate-hypersaline water (Richards and Mullins, 2013). This model evaluates the temporal evolution of metal removal and lipid production using four common marine microalgae species (Nanochloropsis, Pavlova lutheri, Tetraselmis chuii and Chaetoceros muelleri) and shows that after a ten-day period, the microalgae population is able to remove over $95 \%$ of the metals from the solution, paving the way for new strategies of waste stream management based on the use of microalgae-based bioremediation coupled with lipid-production.

\section{Remediation of solid-waste and wastewaters}

Microalgae are also efficient agents for the assimilation of organic matter from various contaminated media. Different photosynthetic organisms, often microalgae/bacteria consortia, have been successfully used in the remediation of solid-waste and wastewaters containing pesticides (González et al., 2012; Jin et al., 2012), phenols (Chiaiese et al., 2011; Maza-Márquez et al., 2014), aromatic hydrocarbons (Ibraheem, 2010; Ghasemi et al., 2011), textile dyes and detergents (Sing-Lai Lim et al., 2010; Singh and Patel, 2012), primarily due to their capacity to metabolize these compounds as nitrogen, phosphorus, carbon, and sulfur sources. For detailed description of the mechanisms involved in the bioremediation of each aforementioned class of pollutants see McGinn et al. (2011).

\section{Photosynthesis-based biosensors}

Real-time monitoring of crop growth parameters and environmental field conditions are mandatory for the development of tailored-made strategies aimed at minimizing resource inputs while maximizing output and yield. In this context, biosensor technology revealed a more suitable tool compared to analytical conventional methods requiring sample pre-treatments and complex instrumentation.

Photosynthetic microorganisms offer versatile solutions for the construction of smart and sensitive biosensors, enabling the detection of even minute amounts of pollutants. The functional principle of these sensors relies on the interaction of some classes of herbicides, pesticides, or heavy metals with a specific pocket of the photosynthetic reaction centers. This evokes physicochemical changes that can be easily converted into measurable electrical signals. For instance, mercury with a $10^{-14}-10^{-6} \mathrm{M}$ concentration range in industrial and agricultural effluents could be detected using Chlorella whole cell based biosensors (Singh and Mittal, 2012). Researchers have also shown that His-tagpurified reaction centers of Rhodobacter sphaeroides attached to a gold electrode are particularly suitable for specific biosensing of herbicides, as photocurrent generation was inhibited in a concentration-dependent manner by the triazides atrazine and terbutryn with a Limit of Detection (LOD) of 50 and $8 \mathrm{nM}$, respectively, but not by nitrile or phenylurea herbicides, opening up suitable protein engineering approaches to develop more sensitive and more selective biosensing devices for the control of weeds (Swainsbury et al., 2014).

Wild-type and genetically engineered strains of the unicellular green alga Chlamydomonas reinhardtii were exploited to develop a set of portable and easy-to-use biosensors. These sensors, making use of photosynthetic biorecognition elements, enabled fast and low-cost pre-screening of triazines, diazines, and ureas in water samples (Buonasera et al., 2009; Scognamiglio et al., 2009). Protein engineering and synthesis of biomimetic peptides also allowed the design of $C$. reinhardtii mutants or novel photosynthetic binding domains with enhanced stability or tolerance to free-radicals-associated stress and heightened sensitivity for triazinic and ureic herbicides (with an LOD in the range of $10^{-8} \mathrm{M}$ ) (Rea et al., 2009; Lambreva et al., 2013; Scognamiglio et al., 2013).

\section{THE USE OF "NATURAL PHOTOSYNTHESIS" IN SOLAR-ENERGY-CONVERTING TECHNOLOGY BIOMASS ENERGY: A CARBON NEUTRAL RESOURCE}

The extensive global use of fossil fuels greatly increased the release of $\mathrm{CO}_{2}$ and other greenhouse gases into the atmosphere leading to important climate changes. There is a dire need for alternative energy sources (Frölicher and Joos, 2010; van Kooten, 2013) and hence biofuels produced from photosynthetic organisms or organic wastes offer the great opportunity to address the world's dependence on oil and to reduce $\mathrm{CO}_{2}$ emissions.

While the burning of fossil fuels increases the $\mathrm{CO}_{2}$ levels in the atmosphere by releasing carbon sequestered millions of years ago, the use of biomass maintains a closed carbon cycle returning carbon previously incorporated by growing plants to the atmosphere (Abbasi and Abbasi, 2010; Kopetz, 2013). Different biomass sources show large variations in terms of yield, quality, and cost. In the past, biomass from food crops, hydrocarbon-rich plants, waste reuse, or weed and wild plants were investigated for energy production and it was shown that the efficiency of massto-energy conversion is related to their biomass composition, i.e., the quantitative proportion between the three main organic constituents cellulose, hemicellulose, and lignin (Irmak et al., 2013; Zeng et al., 2014).

Recently a new energy production line from biomass derived from photosynthetic microorganisms (e.g., algae) has been added to the already known carbon neutral methodologies. While there are still challenges, the results obtained so far show the potential of this innovative approach (Ghasemi et al., 2012; Menetrez, 2012; Adenle et al., 2013).

\section{BIOFUELS GENERATIONS}

The history of biofuels starts with Louis Pasteur in the 19th century who in 1861 observed butanol production from anaerobic fermentation (later on picked up by Chaim Weizmann in 1913 studying acetone-butanol-ethanol fermentations in clostridia growing on a large range of biomass, most notably molasses). In the 1890s, Dr. Rudolf Diesel invented his revolutionary engine designed to run on a wide range of fuels, including vegetable oils, followed by Nicolaus Otto's pioneering spark-ignition engine 
designed to run on ethanol (i.e., derived from plant mass). In the early 20th century petroleum became widely available and the biofuel concept gained little attention except for brief interests during World War II and the 1970s oil crisis. During the last few decades, interest for alternative energy sources was rekindled and different biofuels were introduced on the markets (Kovarik, 2013).

Current biofuels are classified depending on the feedstock type used. The first generation of biofuels, of which ethanol and biodiesel are the main exponents, are essentially derived from food crops such as soybean, wheat, sugar-cane, and corn, using different procedures depending on the type of "green fuel" to be produced (Lee and Lavoie, 2013). The production of ethanol is generally obtained by fermentation of $\mathrm{C}_{6}$ sugars (e.g., glucose) through the action of yeasts, such as Saccharomyces cerevisiae, while biodiesel production requires a chemical process (Park et al., 2013). The treatment includes the extraction of the oil fraction from the edible biomass and its transformation in biodiesel through trans-esterification in the presence of methanol to obtain methyl esters (biodiesel), with glycerol as a by-product. Eventually the green fuel is recovered by repeated washings with water to remove glycerol and methanol (Naik et al., 2010; Lee and Lavoie, 2013).

Despite environmental benefits, the first generation of biofuels was accompanied by concerns about potential drawbacks generated by the competition with food and fiber products as well as by the competition for land and water (Ajanovic, 2011; Lee and Lavoie, 2013; Mohr and Raman, 2013), rising doubts about costs and sustainability and prompting research into the second generation of biofuels.

The second generation of biofuels exploits the potential of cheap, plentiful, non-edible biomass of lignocellulosic nature. This biomass is divided in three subcategories: homogeneous (e.g., wood chips), quasi-homogeneous (e.g., agricultural or forest residues) and non-homogeneous (e.g., municipal wastes) (Naik et al., 2010; Lee and Lavoie, 2013). The production is based on thermochemical or biochemical processes generating different end-products.

The thermochemical pathway transforms the whole biomass into three phase fractions by heat treatment in the presence of different oxygen concentrations: solid (biochar), liquid (bio-oil) and gaseous (syngas), their relative percentage being dependent on the different thermal conditions applied. At low temperatures $\left(250-350^{\circ} \mathrm{C}\right)$ and in the absence of oxygen, torrefaction occurs and mainly biochar is obtained; at higher temperatures $\left(550-750^{\circ} \mathrm{C}\right)$ and in the absence of oxygen, bio-oil is primarily produced through pyrolysis; at very high temperatures (750$1200^{\circ} \mathrm{C}$ ) and in the presence of traces of oxygen, a gasification process occurs, producing mostly syngas. In theory any lignocellulosic biomass can be treated with any of the aforementioned thermo-chemical processes. In practice however technical and economic restrictions need to be considered on a case to case basis (Abbasi and Abbasi, 2010; Naik et al., 2010; Gallagher and Murphy, 2013; Lee and Lavoie, 2013).

The biochemical approach, exclusively applicable on the cellulosic fraction of the biomass, consists of hydrolysis, fermentation, and product separation. The complexity of this method is due to the resistant nature of cellulose (usually requiring a pre-treatment), the plethora of sugars released after breakage, and the need of specific microorganisms (including genetically engineered ones) to obtain an efficient fermentation (Abbasi and Abbasi, 2010; Lee and Lavoie, 2013).

When it became apparent that biofuels based on (micro)algal biomass could potentially provide much higher yields with lower resource inputs, efforts concentrated on the third biofuel generation. Current microalgae culture systems exist as expensive photo-bioreactors or in weather-dependent and contaminationprone outdoor systems (Chen et al., 2011; Halim et al., 2012; Makareviciene et al., 2013), but they do not need valuable farmland and their impact on fresh water resources are minimal if water is recycled or when waste waters or industrial effluents are used. Their potential is also given by an excellent photosynthetic performance, a good tolerance to hostile environmental conditions (Singh et al., 2011a,b; Larkum et al., 2012; Allen et al., 2013; Borowitzka and Moheimani, 2013), and a great variety in content and lipid profiles depending on the used species, growth conditions, and medium composition (Halim et al., 2012; Nascimento et al., 2013).

The conversion process from (micro)algal biomass to biofuel starts with harvesting and dehydration. Collection can be realized by centrifugation, filtration, or flocculation. The latter method, having the lowest energy cost, is usually achieved through the addition of polymers to the suspension (Vandamme et al., 2013). After removal of most of the liquid, a pre-treatment (cellular decomposition by high-pressure homogenization, total dehydration, and milling to fine powder) is required to optimize the material for lipids extraction (Halim et al., 2012; Pahl et al., 2013) carried out by using organic solvents or supercritical fluids (e.g., highly pressurized liquid carbon dioxide-see below). Eventually the mixture is filtered to remove cellular debris, while extraction solvents and residual water are eliminated by distillation, vacuum evaporation or solid- phase solvent adsorption. The final product consists of a lipid crude extract, usually containing polar and non-acylglycerol lipids. Before trans-esterification, the fraction of non-acylglycerol lipids, considered a contaminant in the biofuels production, is removed by liquid chromatography, acid precipitation and urea crystallization. During the trans-esterification, fatty acids are converted to alkyl esters in the presence of alcohols. The final mixture is purified to remove chemical contaminants and finally allowed to settle by gravity. Within the biphasic mixture, the top part consists of the biofuel, whereas the bottom part is glycerol. After decantation and several washings, the composition of biodiesel is analyzed by gas chromatography (Halim et al., 2012; Makareviciene et al., 2013).

The production of fuel starting from a genetically modified algae biomass, capable of going beyond the sustainable production of energy, is the goal of the next generation of biofuels. This could be achieved through new algae strains that are able to capture and store excess $\mathrm{CO}_{2}$ thus acting as a carbon negative rather than carbon neutral source (Lü et al., 2011; Liew et al., 2014).

Despite many advantages, there are still technological and economic limitations in the production chain of biofuels from algae. The main obstacles are in the selection of algal strains and in the development of an efficient lipid extraction process economically 
favorable for production at the industrial scale (Aransiola et al., 2014; Liew et al., 2014).

In particular, the ideal (micro)algal strain for biofuel production should have high lipid productivity, high $\mathrm{CO}_{2}$ fixation capacity, limited nutrient requirements, a fast growing cycle, high photosynthetic efficiency, outcompete contaminant strains in open pond production systems, be able to produce valuable co-products, and display self-harvesting characteristics (Brennan and Owende, 2013). Currently, there is no (micro)algal strain with all these requirements. Though genetic engineering-inspired modeling will be the tool for success, this remains limited to a few algal laboratory model strains, and additional genome sequencing of strains with appropriate features is required. Microalgae can potentially produce 100 times more oil per acre land as compared to any terrestrial oil-producing crop (wwwl.eere.energy. gov/biomass; Singh et al., 2011a) which remains, in spite of the fact that the current cost of microalgae per unit mass is higher (Greenwell et al., 2010), an attractive point in terms of lowering fossil fuel dependency.

\section{BIOREFINERY}

The generation of a variety of bio-based products next to the production of energy would significantly maximize the value of the used feedstock (Azapagic, 2014). This is achieved taking advantage of various components present in the biomass as well as by adopting different technologies and processes. In particular, microalgae and cyanobacteria show potential since, in addition to biofuel precursors, carbohydrates and cellulose (ideal for the production of fine chemicals), they also produce pigments (e.g., phycocyanine, carotene, astaxanthin) and antioxidants useful in pharmaceutical and cosmetical applications, vitamins, and bioactive peptides (e.g., with antihypertensive, anticoagulant, antiviral or antimicrobial activities), and can be very rich in proteins making them suitable for the food and animal feed market (Vanthoor-Koopmans et al., 2012; Jarda et al., 2013; Uggetti et al., in press).

A current trend in the biorefinery is the use of biomass from bacteria and algae associated with wastewater treatment (Olguín, 2012; da Silva et al., 2013; Rawat et al., 2013). The dual purpose of this system makes it one of the most promising strategies in microalgae exploitation owing to the cost-effective and competitive production. Additional studies are required, since there are still limits in the development of an efficient procedure for the separation of the different fractions and for the preservation of the compounds of interest.

\section{EVALUATION OF ENVIRONMENTAL AND SOCIAL IMPACTS OF BIOMASS ENERGY PRODUCTION}

Conversion, use and accessibility of energy are basic concepts of sustainability, which need to be coupled to acceptable social, economic, and environmental dimensions. In order to guarantee societal benefits of biofuels production, governments, researchers and companies will need to cooperate in carrying out assessments, mapping suitable areas, defining, and applying national, and international standards, as well as enhancing commercial-scale production (Singh and Olsen, 2012; Rathore et al., 2013).
Lately, a new tool for sustainability assessment of biofuels has been introduced: LCA, which helps policy makers in their choice of the most appropriate biofuels for specific purposes (Clay and Fong, 2013; Kendall and Yuan, 2013).

According to the US Environmental Protection Agency (EPA) a complete LCA process of biofuels includes the evaluation and analysis of every single step of production, from raw material to harvesting, processing, and transport, to their storage and distribution, and to their final use (http://www.epa.gov/nrmrl/std/ lca/lca.html). The LCA approach has proven a valuable method in understanding the environmental impacts generated by various industrial products during their production, and is now the foremost accepted methodology for the assessment of environmental impacts (e.g., eutrophication, soil erosion, water run-off, loss of natural biota, and land resources) related to the introduction of new-technology fuels (Singh and Olsen, 2012; Ajayebi et al., 2013).

\section{BIOFUELS: CURRENT SITUATION AND NEW SCIENTIFIC RESEARCH TRENDS}

The global scenario of "green fuel" production is still imprinted by the presence of first generation biofuels. Main producers of bioethanol are the United States and Brazil and soybean and sugarcane sucrose biomasses are the traditional feedstocks for biodiesel (Koçar and Civaş, 2013; Avinash et al., 2014). However, a trend toward large-scale production of biofuel exists. In Australia the current strategy is to increase the biofuel industry potential by exploiting marginal lands for exotic plant cultivation, while in India many venture assets presently concentrate on the use of invasive and non-edible plants for alternative energy production, even if the use of invasive plants for biofuel is not economical nor sustainable.

Concerning the production of third generation biofuels, strong support comes from scientific research in Europe, China, and the United States, with an emphasis on biomass yield improvements and the exploitation of genetic engineering tools. Several strategies are under investigation to overcome the limitations of large-scale production and to expand the market of this alternative source of energy. In particular, studies on microalgae and plants are aimed to control carbon portioning during photosynthesis within the cells (Liberton et al., 2013; Melis, 2013). This could result in higher yields and quality improvements of the final products. A recent example is the heterologous expression of the entire isoprene biosynthetic pathway in the cyanobacterium Synechocystis PCC 6803 (Bentley et al., 2014).

Another experimental approach aimed at increasing the biomass productivity concerns the RUE enhancement by modulating light capture at the antenna complex. This can be achieved either by optimizing the light distribution within the plant canopy, by extending the PAR spectrum, or by size reduction of the light harvesting antenna (see section Improving Canopy Photosynthetic Performance). Genetic engineering plays a key role in the manipulation of microorganisms, addressing the improvement of their growth rate, production and accumulation of their metabolites and precursors, and harnessing their defenses against microbial competitors, while simplifying harvesting methods (Gimpel et al., 2013; Shurin et al., 2013; Leite 
and Hallenbeck, 2014). Bacteria have been engineered to produce a wide range of chemical compounds closely related to fuel molecules, and synthetic biology approaches were applied for the production of advanced biofuel targets (Choi and Lee, 2013; Gronenberg et al., 2013; Wen et al., 2013). Molecular biology also enabled the production of specific yeasts and algae used in biofuel platforms. In particular, engineered yeast cells producing alcohols, sesquiterpenes, and fatty acid ethyl esters have been used for advanced biofuels with improved yield. Furthermore algae have been genetically manipulated to optimize their fatty acid biosynthesis, hence to increase oil content, or to optimize acid chain length for more stable algal biodiesel (Buijs et al., 2013; Gimpel et al., 2013). The CoA carboxylase enzyme, involved in the rate-limiting step in fatty acid biosynthesis, is one of the primary targets for the increase of algal oil yields (Mühlroth et al., 2013). Likewise, to control fatty acid chain length and hence biodiesel quality, thioesterases that terminate the chain elongation in fatty acid biosynthesis and functionally determine the identity of the end product are targeted as well (Blatti et al., 2013).

Research also focuses on the improvement of technologies concerning the collection and the conversion of algal biomass. An efficient harvesting method is a major challenge for the algal biofuel commercialization. Although sedimentation and flocculation seem to be the best low-cost methods they are not suited for all microalgae strains (Vandamme et al., 2013). New methodologies need to be developed and efforts are currently directed toward genetic modification to improve algae collection through the promotion of cell aggregation and the ability to flocculate more easily (Mendez et al., 2009; Scholz et al., 2011).

A recent challenge related to the conversion of algal biomass into biofuel is to achieve a single-step procedure. The development of a "supercritical approach" allowing the direct conversion of wet algae to crude biodiesel is under investigation (Patil et al., 2012; Reddy et al., 2014). It has been shown that supercritical carbon dioxide extracts lipids from algae with more efficiency and higher selectivity than traditional solvent separation methods, while extract purity and the final product concentration remain high. A further improvement would be combining the process of supercritical $\mathrm{CO}_{2}$ lipid extraction with the use of a suitable solid catalyst to allow extraction and conversion at a single production site (Soh et al., 2014).

The hydrothermal liquefaction for biomass conversion is also an appealing procedure and is particularly suitable for the direct treatment of wet feedstocks (Kruse et al., 2013; Chen et al., 2014; Cheng et al., 2014; Li et al., 2014). This technology allows simultaneous production of value-added compounds and bio-oil from algal biomass while a one-step process for direct liquefaction and conversion of wet algal biomass under supercritical methanol conditions should be possible (Patil et al., 2011).

\section{BIO-BASED POLYMERS}

Plastics play a major role in a sustainable development. Being both affordable and highly versatile, they have become essential to meet necessities in sectors such as health, shelter, communication, transportation, and food and energy security. Considering the growing demand for polymer products it is necessary to identify those production procedures which provide the lowest environmental impact and carbon footprint. While the exploitation of fossil feedstock in the manufacturing of plastics represents a sustainable and effective use of oil and gas, the most successful approach to bio-based polymers is to produce monomers (having at least two reactive groups or one $\mathrm{C}=\mathrm{C}$ bound) from biowaste and from "renewable oil" obtained from biorefineries and through plastic degradation. This, in combination with a meltand gas-phase polymerization process, provides renewable and bio-degradable plastics without impairing their intrinsic characteristics (Mülhaupt, 2013). Examples of bio-based, renewable monomers are ethylene (for poly vinyl chloride or polyethylene glycol) e.g., from bioethanol, diamines (for polyamides and isocyanates) e.g., from amino acids and sugars, phenols (for polycarbonate or polyepoxides) e.g., from lignin, and polyols (for polyurethanes) e.g., from carbohydrates.

\section{SOLAR-ENERGY-CONVERTING TECHNOLOGY MIMICKING NATURAL PHOTOSYNTHESIS}

The energy efficiency of natural photosynthesis, defined as the ratio of energy content of the annually harvested biomass versus the annual solar radiation over the same area, rarely reaches $1 \%$, with a theoretical maximum for algal biofuels of $4.5 \%$ (Blankenship et al., 2011; Barber and Tran, 2013; Frischmann et al., 2013). As a consequence, biomass-based energy production could provide a limited contribution to our future energy demand. However, the high efficiency of light-harvesting (quantum efficiencies $>90 \%$; defined as the probability that an excitation leads to charge separation; Şener et al., 2011) and lightdriven water oxidation ( $>80 \%$ in low light conditions; Ananyev and Dismukes, 2005) inspire the development of innovative solar-energy-converting technologies.

\section{PHOTOVOLTAIC CELLS}

Photosynthesis consists of a subset of energy conversion processes which can be mimicked in solar energy harvesting devices (Andreiadis et al., 2011). At the most basic level this implies the conversion of sunlight into charge-separated states by which an electron is freed from a light-absorbing semiconductor material (often silicon doped with impurities). The empty space left behind at the site of the electron-emitting atom is often referred to as a "hole." Photo-generated electrons are conducted toward an acceptor material while holes-which behave as mobile positively charged particles-diffuse into the opposite direction. This separation of hole-electron pairs (called "excitons") into free electrons and holes is expressed as the photovoltage and is the source of usable electrical energy.

Thus, photovoltaic devices generate electrical energy under illumination by exploiting semiconductor material or molecular photosensitizer for light-induced charge separation. While photovoltaic technology is already implemented at a global scale, the search for cheaper and less energy demanding materials for device fabrication is ongoing. One class of alternative materials for light induced charge separation includes the components of natural photosynthesis, the photosystem protein complexes. Their extreme quantum efficiency and large natural abundances makes them highly suitable for biohybrid photovoltaic devices (Barber and Tran, 2013; Frischmann et al., 2013). 
The major consideration is how to avoid charge recombination when photosynthetic biomolecules are integrated in photovoltaic devices since the charge carrier produced should not be quenched at the photoelectrode it originates from but readily transferred to the counter electrode, preferably close to the circuit for effective power generation. A number of complete photovoltaic cells based on photosystem 1 (PS1) and/or photosystem 2 (PS2) are described below.

The first generation of biophotovoltaic cells based on isolated photosynthetic proteins incorporated semi-conducting electron transport layers to interface the biomolecules with the electrodes (Das et al., 2004). A later concept followed dye sensitized solar cell (DSSC) technology. In DSSC, the intrinsic properties of semiconductor materials with high overpotential for specific electron transfer processes are exploited to limit charge recombination processes. The same principles were applied for the construction of a PS1-semiconductor hybrid photoanode (Mershin et al., 2012). The semiconductor properties coupled to the high surface area electrode yielded the highest energy conversion efficiency reported to date for a biophotovoltaic device $(0.08 \%)$. Still, the performance of the hybrid system remained well below that of state-of-the-art photovoltaic devices. Moreover, biophotovoltaic concepts much rely on the properties of the semiconductor material. The energy-costly fabrication and the light-induced charge separation properties of the semiconductor may thwart the advantage of implementing the biological component. Thus, for photosystem-based hybrids to make any significant impact in sustainability schemes, suitably conductive and cheap electrode materials must be found.

Yehezkeli et al. (2012) reported on a biophotovoltaic cell that fully excluded semiconductors but instead was based on a PS2 photoanode in combination with an oxygen reducing biocathode. Upon charge separation at the PS2 anode, water becomes oxidized and the produced oxygen diffuses to the cathode where it is reduced back to water via an enzyme-catalyzed process. The irreversible electrochemical properties of the charge carrier, oxygen, ensure that its reduction only takes place at the catalyst-modified biocathode. Charge recombination of oxygen at the PS2 photoanode is slow, and short-circuiting is therefore impeded. This concept was recently extended to the combination of a PS2 photoanode with a PS1-based oxygen-reducing photocathode (Kothe et al., 2013a,b; Hartmann et al., 2014). In this approach, oxygen is again exploited as the charge carrier. The additional charge separation step at PS1 allows to couple a catalyst for $\mathrm{H}_{2}$ evolution or other irreversible reductive processes. This provides the basis for the development of semi-artificial devices that fully mimic the two solar energy conversion steps in natural photosynthesis (Figure 2) (Kothe et al., 2013a,b; Hartmann et al., 2014).

The above illustrates how charge recombination can be avoided by exploiting irreversible charge carriers such as oxygen in the PS2-based devices. However, bringing PS1 in contact to a conductive electrode is more challenging since, in contrast to PS2, PS1 does not catalyze an irreversible chemical reaction but instead exchanges electrons with reversible redox partners. Hence, freely diffusing charge carriers will recombine with each other or with the electrode. The main strategies to minimize such recombination losses rely on (i) contacting both the electron-accepting and

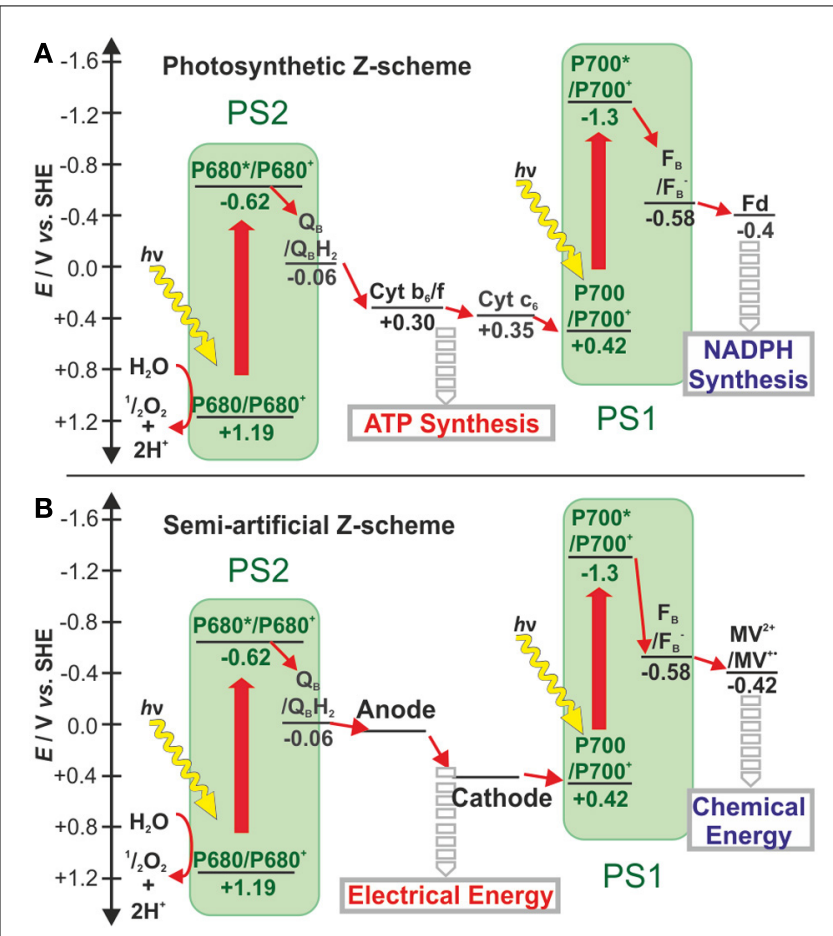

FIGURE 2 | Schematic comparison of electron transfer chains in (A) natural photosynthesis and (B) semi-artificial photosynthesys diplaying the Z-scheme for the conversion of solar light to electrical and chemical energy - adapted from (Kothe et al., 2013a,b). Electron transfer steps are shown as small red arrows while light-induced charge separation steps are depicted as large red arrows. In natural photosynthesis, the electron transfer from $\mathrm{Q}_{\mathrm{B}}$ in PS2 to P700 in PS1 creates a chemiosmotic potential further exploited for ATP synthesis. The high-energy electrons exiting PS1 are transferred via Fd to FNR for NAPD+ reduction to NADPH. In the semi-artificial Z-scheme the electron transfer chain between PS2 and PS1 is shortcut by electrodes to recover the energy as electricity. In addition, PS1 transfers its electrons to methyl viologen, an artificial charge carrier. The latter is envisioned to mediate these electrons to catalysts such as hydrogenases for chemical energy production (Haehnel and Hochheimer, 1979). Cyt $c_{6}$ : cytochrome $c_{6}, C b_{6} f$ :cytochrome $b_{6} f$ complex, Fd, ferredoxin; FNR, ferredoxin:NADP ${ }^{+}$oxido reductase; $\mathrm{MV}^{2+}$, methyl viologen). Potentials are given in volt (V) versus the standard hydrogen electrode (SHE).

the electron-donating sides of PS1 with surface-confined electron relays or (ii) direct electron transfer between the two electrodes. Here, the challenge resides in the actual cell fabrication since PS1 needs to be inserted into a nanogap between the two electrodes. The underlying concept was shown at the single molecule level in a double junction involving direct electron transfer (Gerster et al., 2012). Although the electric current density and open-circuit voltage of such a bionanodevice opens up prospects for highly efficient biophotovoltaics, upscaling this concept to a large surface area may be difficult since defects in the nanogap would result in direct short-circuits between the two electrodes (Plumeré, 2012). A large-scale device that fully excludes the use of semiconductor material still needs to be demonstrated.

To date, efficiencies of devices that deploy biological components for light-induced charge separation have not yet exceeded $0.1 \%$, which is well below those seen for standard semiconductor 
photovoltaics. A further improvement in performance requires alternative strategies to circumvent charge recombination, in particular for PS1-based devices (Kothe et al., 2014). One approach that has been overlooked so far is to mimic the role of NADPH in nature i.e., the role of $\mathrm{O}_{2}$ in the PS2-based system, namely to develop for PS1 an electrochemically irreversible charge carrier that requires a catalyst for electron transfer. Also, an enhanced loading of photosynthetic protein may eventually result in higher photocurrent densities. When the electronic communication between the photosynthetic protein and the electrode is based on a monolayer design, porous high-surface-area electrodes may be used. However, this would imply the use of transparent materials therefore rely on expensive semiconductors. Instead, the technological trend may move from monolayer layouts toward multilayers that are contacted via conducting polymeric matrices. In this case, transparency and electron transfer properties within the polymer-protein hybrid film must be further developed to realize highly efficient biophotovoltaic systems. Moreover, in the development of high performance biophotovoltaics, the stability under illumination is also a critical factor. In this regard, since PS1 is more stable as compared to PS2, the former may yet be better suited for the development of energy conversion devices.

\section{FULLY-INTEGRATED ARTIFICIAL PHOTOSYNTHETIC SYSTEMS}

The term artificial photosynthesis was coined for the first time to make a distinction between conventional silicon-based and novel dye-sensitized solar cells (DSSC) (Grätzel, 1991). In contrast to the direct electron transfers from the silicon atoms upon light absorption, the DSSC separates light absorption by "sensitized" metal-complexed or organic metal-free dye molecules which subsequently inject electrons into semiconducting material. This way, energy conversion efficiencies of up to $10 \%$ can be obtained (Nazeeruddin et al., 1993). Although the original DSSC necessitates a liquid electrolyte, affecting device stability, recent advances have shown the possibility for these solar cells to perform well as solid state devices using hybrid perovskite dyes (Burschka et al., 2013). Perovskite-based technologies and architectures for solar cells are constantly being improved and they show great promise for the realization of artificial photosynthesis (Zhou et al., 2013; Christians et al., 2014).

The success of the DSSC in terms of efficiency and cost effectiveness has been an important driver for artificial photosynthesis research targeting the more complex energy conversion processes of natural photosynthesis. A major target to mimic are the reactions that involve the splitting of water. While in natural photosynthesis the protons form a gradient across the cell membrane to drive ATP synthesis, energy conversion devices rely on the subsequent formation of molecular hydrogen as a combustible fuel. In the realm of semiconducting materials, water splitting is achieved by means of solar cells that generate high photovoltages. In a hybrid technology the semiconducting material is interconnected with catalytic material to enhance the process. Concomitantly, catalytic material is being developed to replace the platinum, a highly precious metal, generally employed for hydrogen formation. Significant progress has been made especially for artificial water-splitting by the discovery of a cobalt-based catalyst that can be incorporated into energy conversion devices. In the past few years fully integrated devices operating on these principles have been reported (Reece et al., 2011; Zhao et al., 2012; Abdi et al., 2013).

In spite of a promising 10\% energy conversion efficiency-the minimal standard to make an impact at an industrial scale-for some of these devices, they are not yet commercially competitive with fossil fuels and in the past two decades DSSC efficiency could not be significantly improved. The search is therefore for "dirt cheap" materials, available at low fabrication costs but available in great abundance. Chemically synthesized supramolecular systems can act as homogeneous devices that simultaneously enable light absorption, electron transfer and catalysis. Promising novel materials are dyads, triads, or more complex supermolecules (Megiatto et al., 2012) but they have not yet been integrated within a photovoltaic device. Other potentially very cheap molecular systems consist of photovoltaic solar cells made of conducting polymers doped with dye molecules (Liang et al., 2010). Like all moleculebased solar cells, such devices need to address stability issues under long term operation and resilience toward air (Brabec et al., 2010).

Possibly the cheapest material imaginable is the actual photosynthetic machinery found in photosynthetic organisms. At the level of proteins and protein complexes, the catalytic material is ready-made with proven functionality, consists of ubiquitous substances, and is powered by solar energy while assembled by utilizing carbon dioxide. Most research to date focuses on the interconnection of protein complexes with conducting materials. Some fully integrated photovoltaic devices may serve as proof of principle despite very low efficiencies (Das et al., 2004; Mershin et al., 2012). The main target for artificial photosynthesis beyond photovoltaics is the implementation of PS 1 complexes, generating high energy electrons. In conjunction with platinum electrodes or nanoparticles, photogenerated electrons can be employed for hydrogen generation (Grimme et al., 2008; Iwuchukwu et al., 2009). Complemented with PS 2 and a hydrogen evolving enzyme, a complete biohybrid device can be envisioned (Badura et al., 2006). To date only partially integrated systems, consisting of PS1 complexes fused with hydrogenase for homogeneous catalysis (Ihara et al., 2006) or photoelectrochemical catalysis on gold (Krassen et al., 2009) have been reported.

An additional development is the capture of carbon dioxide and its photoelectrochemical conversion to carbonhydrogen molecules (Spinner et al., 2011). Ideally this conversion reaction would yield a gas or fluid fuel that might be easier to handle than hydrogen gas. Future devices incorporating such reactions will likely compare to those currently used for bulk chemical synthesis, allowing the use of existing factories, and hence they could rapidly become cost effective.

\section{IMPLICATIONS OF OXYGENIC PHOTOSYNTHESIS FOR HUMAN SPACE EXPLORATION AGRICULTURE IN SPACE}

Photoautotrophic organisms such as green plants and alga, and cyanobacteria, are essential to support human life in long-term stationary or interplanetary missions because they scrub the crew's air of carbon dioxide by athmospheric fixation, produce oxygen, adjust humidity or recycle wastewater, and convert 
organic wastes back into edible mass. Physical factors in space that might affect photosynthesis and carbon utilization are solar and cosmic radiation, gravity, temperature, hypobaria, humidity, light, and the absence of an Earth magnetic field (i.e., at the Moon and at Mars). Because earth organisms are evolutionary ill prepared for microgravity $\left(10^{-6}-10^{-3} \mathrm{~g}\right)$, fractional gravity $(0.17 \mathrm{~g}$ for the Moon, $0.38 \mathrm{~g}$ for Mars), or cosmic radiation, much space research on photoautotrophs has focused on the biochemical or physiological effects of real or simulated low gravity and ionizing radiation. For agriculture in space the deployment of microalgae may be particularly rewarding as some are very nutritious and can be directly consumed with little processing. They also respond much faster to environmental changes and hence are easier to investigate. Moreover, microalgae are generally robust organisms with highly efficient photosynthesis and are ideal organisms for life support systems (LSS) as they can grow in panel- or tube-fitted reactors within limited confinements (see further and review by Saei et al., 2013).

\section{Microgravity and ionizing radiation: physical constraints of sustained life in space?}

Because of the constant presence of a gravity vector on Earth, plants have learned to use this force for many biological functions and mechanisms. Hence, the loss or change of gravity alters the way in which plants sense and respond to environmental cues. For instance, Arabidopsis hypocotyls growing in microgravity at the ISS display a novel phototrophic response to red light, which is suppressed at 1-g simulated gravity using an on-board centrifuge and in ground controls (Millar et al., 2010). Likewise, seedlings pre-treated with red light experienced a more pronounced bluelight-induced phototropism in microgravity as compared to 1-g controls. Later studies at the ISS confirmed these effects and showed that $0.1-0.3 \mathrm{~g}$ sufficed to attenuate the red-light-based phototropism while at a gravity of $0.3 \mathrm{~g}$ or above, blue-light phototropism was no longer enhanced. Clearly, conditions at the ISS provide a unique environment to address fundamental questions in space biology (Olsson-Francis and Cockell, 2010; Paul et al., 2013). Importantly, plants grown in the reduced gravities of the Moon $(0.17 \mathrm{~g})$ and Mars $(0.38 \mathrm{~g})$ are not necessarily exposed to gravity-related stress and so might function normally as if they were on 1-g Earth (Kiss, 2014). Still, more studies with more plants are needed to define the exact threshold for gravity as a prerequisite to (normal) plant life.

In terms of radiation, total dose rates ${ }^{1}$ within Low Earth Orbit spacecraft (somewhere between 160 and $2000 \mathrm{~km}$ above the Earth's surface) average from $150 \mu \mathrm{Gy} \mathrm{d}^{-1}$ to $500 \mu \mathrm{Gy} \mathrm{d} \mathrm{d}^{-1}$ (Benton and Benton, 2001; Goossens et al., 2006; Vanhavere et al., 2008) as compared to the Earth background radiation levels of circa $1-3 \mu \mathrm{Gy} \mathrm{d}^{-1}$ at sea level. During the Apollo missions, with lunar surface exploration lasting $21-75 \mathrm{~h}$ and full passage through the Van Allen belts, but no enhanced solar activity, dose rates measured between 180 and $1270 \mu \mathrm{Gy} \mathrm{d}^{-1}$ (Bailey, 1975). Dose rates at the lunar surface were measured between 200 and

\footnotetext{
${ }^{1}$ Dose rates represent the amount of energy deposited per unit mass, with 1 Gy being $1 \mathrm{~J} / \mathrm{kg}$. Health risks are generally expressed in $\mathrm{mSv} / \mathrm{yr}$, applying organ-specific and radiation type-specific quality factors.
}

$360 \mu \mathrm{Gy} \mathrm{d}^{-1}$. Comparably, based on $\sim 300$ days of observation by the Mars Curiosity Rover science laboratory (MSL), the daily space radiation dose at Mars' surface averaged at $210 \mu \mathrm{Gy} \mathrm{d} \mathrm{d}^{-1}$ which was enhanced by roughly $30 \%$ during the Solar Particle Event (SPE) of 11 and 12 April 2013 (Hassler et al., 2014).

The survivability after irradiation has been documented for some organisms in terms of the acute lethal dose $\left(\mathrm{LD}_{50}\right.$ in parentheses): humans ( $4 \mathrm{~Gy})$, mice (4.5 Gy), chicken (10 Gy), fruit fly (640 Gy), onion (20 Gy), wheat (43 Gy), potato (120 Gy), tomato (150 Gy), amoeba (1 kGy), tartigrades (5kGy), algae (60 Gy$1.2 \mathrm{kGy})^{2}$, and bacteria (60 Gy-30 kGy) (see also http://www. unscear.org). A few cyanobacteria (Anabaena torulosa, $5 \mathrm{kGy}$, (Singh et al., 2010); Croococcidiopsis sp. 029, $15 \mathrm{kGy}$, (Billi et al., 2000) and algae [Coccomyxa actinabiotis, $20 \mathrm{kGy}$, (Rivasseau et al., 2013)] have been reported as being highly resistant against radiation although the underlying mechanisms have not yet been studied. While it is reassuring that yearly radiation dose rates in space or on the Moon or on Mars will remain below $1 \mathrm{~Gy}$ so that growth of plants and microalgae or cyanobacteria will not be impaired, it is obvious that such dose rates may cause DNA mutations with potential detrimental effects. Hence, extensive research on the effects of cosmic radiation on these organisms, in particular for chronic exposures, is fully warranted.

\section{A brief history on space biology of plants (and microalgae/cyanobacteria)}

Plant research in space started in 1971 with a tiny greenhouse called Oasis, at Salyut 1. After many setbacks in the following decade, arabidopsis grown on Salyut 7 finally produced viable seeds and wheat and mustard were later successfully grown (Ivanova et al., 1993; Mashinsky et al., 1994; Salisbury and Clark, 1995). Meanwhile, at the Spacelab module, a European-American venture, unaware of the earlier Soviet results, encountered (and overcame in 1996) the same developmental problems of spacegrown plants (Freeman, 1998; Ivanova et al., 1998). The main culprit appeared to be ethylene, which acts as a hormone and is produced by most plant organs (Chaves and Mello-Farias, 2006). On Earth, ethylene is dispersed by air movement but not so in microgravity where it surrounds the plant, enhancing withering and promoting male sterility. Hence, space greenhouses were fitted with fans and ethylene filters and equipped with humidity, $\mathrm{CO}_{2}$, temperature, and oxygen sensors so that the seed-to-seed cycle in space could be finally realized (reviewed by Casado, 2006).

Plants have also been studied when exposed to the open space environment in the EXPOSE-E missions (Rabbow et al., 2012) outside the ISS. At low shielding, an average dose rate of $400 \mu \mathrm{Gy}$ $\mathrm{d}^{-1}$ was measured, with a total exposure dose of $215 \mathrm{mGy}$ at the lowest shielding (Berger et al., 2012). Remarkably, seeds of $A$. thaliana and Nicotiana tabacum (tobacco) could still germinate after 1.5 years exposure-which also included solar UV, cosmic radiation, temperature fluctuations, and space vacuum (Tepfer et al., 2012). During the same EXPOSE-E mission, it was shown that some cyanobacteria and green algae survived the same length of direct exposure (Cockell et al., 2011; Onofri et al., 2012).

\footnotetext{
${ }^{2}$ IAEA Technical Report series 172, Vienna, Austria, 1976.
} 


\section{Technological advances for "green" research in space}

Novel lighting technologies for space green houses make use of light-emitting-diodes (LEDs) which are more durable and reliable than the conventional light sources and allow to simulate parts of the spectrum not present in traditional lighting. They can also emit photons within very narrow bands of the spectrum, i.e., only wavelengths needed by the photosynthetic organisms, hence saving energy. The growth of plants (or microalgae/cyanobacteria) on narrow bands of the spectrum is very useful because some chlorophylls use mostly blue and red wavelengths. For instance, red LEDs were used as a photon source in the Astroculture3 growth chamber (Massa et al., 2006).

Advanced methods of soil-free plant growth are crucial to the future of agriculture in space. Such hydroponic and aeroponic systems (http://en.wikipedia.org/wiki/Hydroponics) require less water, allow recycling and better uptake of nutrients, can be better controlled, and can be stacked in confined spaces ("vertical farming"). Although they are energy-demanding as they incorporate lighting, pumping, and air moderation, they may form the key for the long-term colonization of Mars and the moon where nutritious perlite-like minerals could be extracted from local soils and where energy production from solar or nuclear energy is not an important issue. In addition, hydroponic and aeroponic methods can be integrated into bioregenerative life support systems (Paradiso et al., 2014)—see further.

Another important aspect is improved greenhouse equipment. For instance, the Commercial Plant Biotechnology Facility (CPBF; www.nasa.gov) integrates Astroculture ${ }^{\mathrm{TM}}$ technologies, state-of-the-art control software, fault tolerance and recovery technologies, and telescience capability. It also includes LED technology (red and blue at 670 and $450 \mathrm{~nm}$, respectively) and a Fluorescent Light Module (FLM) using high output bi-axial tubes to ensure maximum photon flux. Lately, attention is being directed toward plant growth under fractional gravity in a prelude toward space biology in reduced gravities of the Moon and Mars. In 2015, NASA will attempt to grow arabidopsis, basil, sunflowers, and turnips on the Moon ( 0.17 g gravity) in small aluminum cylinders brought to the Moon by a robotic spacecraft, the Moon Express lander. Later, similar small greenhouses will be tested at Mars.

Today, "-omics" developments have proliferated the amount of genomic information to a staggering level. Since the Arabidopsis Genome Initiative in 2000, many more plant genome sequences were obtained, including for instance those of $\mathrm{C} 4$ crops sorghum, maize, and millet, and the C3 crops wheat, barley, rice, soybean, flax, mustard, cucumber, tomato, potato, banana, peach, pear, apple, orange, and wild strawberry. The genome sequencing of microbes gained equal pace with currently around 2500 bacterial and 150 eukaryal genomes fully sequenced, including 71 cyanobacteria and 7 green algae (http://genomesonline.org/). More cyanobacterial and algal genome projects are planned or on-going. For plants, genome projects exist for peanut, chestnut, lettuce, sugar beet, water melon, and coffee. This sequence information can be put to use for the genetic modification of space-dedicated crops or biosphere-supporting bacteria, while genetic responses induced by space conditions will be better understood.

\section{LIFE-REGENERATIVE SUPPORTING SYSTEMS}

A person in space needs at least $22.4 \mathrm{~kg}$ of food, water, and oxygen per day (Nelson et al., 2003). For a crew of three astronauts flying to Mars and back, with the fastest return currently achievable i.e., without landing on the Martian surface, an estimated 34 tonnes of supplies would be required. It would be impossible to launch and carry this bulk of weight from Earth. Hence material recycling is the only solution and successful food production in space is thus essential. Microalgae, next to plants, claim a prominent role in food supply routes of Moon or Mars stations but they particularly come into play in spacecraft where weight and volume are critical issues (Hendrickx and Mergeay, 2007; Tikhomirov et al., 2007). The green alga Chlorella and the multicellular cyanobacterium Arthrospira (aka Spirulina) already have proven their nutritious value and are now globally commercialized-for full review see Chacón-Lee and González-Mariño (2010).

The purpose of Life Support Systems (LSS) is to transform waste and regenerate air, water, and food. Whereas physicochemical LSS are based on filtration rounds, chemical treatments, and transition processes, bioregenerative LSS (BLSS) use microorganisms and/or plants for oxygen production and carbon dioxide reduction. The main experimental BLSS that use plants and microalgae and that recycle products in a closed loop are summarized in Table 1.

Perhaps the currently best studied system is MELiSSA (Micro Ecological Life Support System Alternative) funded by the European Space Agency (ESA). It consists of four interconnected biological compartments and is completely reliant on photosynthesis. Food and oxygen are produced in the photosynthetic compartment consisting of a plant chamber (IVa) and a microalgae cultivation unit (IVb) (Figure 3). Preferred plant species are those that provide protein-rich food with high nutritious value, such as wheat, soybean, and potato, next to other crops like rice, tomato, lettuce, spinach, and onion (Paradiso et al., 2014). For IVb the cyanobacterium Arthrospira sp. PCC 8005 was chosen as Arthrospira species are efficient photoautotrophs that produce

Table 1 | The main experimental BLSS that use plants and microalgae and that recycle products in a closed loop.

\begin{tabular}{|c|c|c|c|c|}
\hline System & Country & Period & Microorganism & References \\
\hline BIOS & Russia & 1960 & Chlorella & Gitelson et al., 1989 \\
\hline CEBAS $^{a}$ & Germany & 1985 & Chlamydomonas & $\begin{array}{l}\text { Blüm, 1992; Blüm } \\
\text { et al., } 2003\end{array}$ \\
\hline MELiSSA ${ }^{b}$ & $\begin{array}{l}\text { Bel, Fra, } \\
\text { Spa, Can }\end{array}$ & 1988 & Arthrospira & $\begin{array}{l}\text { Mergeay et al., 1988; } \\
\text { Hendrickx et al., } \\
\text { 2006; Lasseur et al., } \\
2011\end{array}$ \\
\hline CERAS ${ }^{a}$ & Japan & 1997 & $\begin{array}{l}\text { Euglena, } \\
\text { Chlorella, } \\
\text { Arthrospira }\end{array}$ & $\begin{array}{l}\text { Takeuchi, 1997; Omori } \\
\text { et al., 2001; Takeuchi } \\
\text { and Endo, } 2004\end{array}$ \\
\hline CAES $^{a}$ & China & 2004 & Chlorella & Wang et al., 2007 \\
\hline
\end{tabular}

${ }^{a}$ contains also an aquatic animal habitat.

${ }^{b}$ http://ec/s.esa.int/ecls/ 


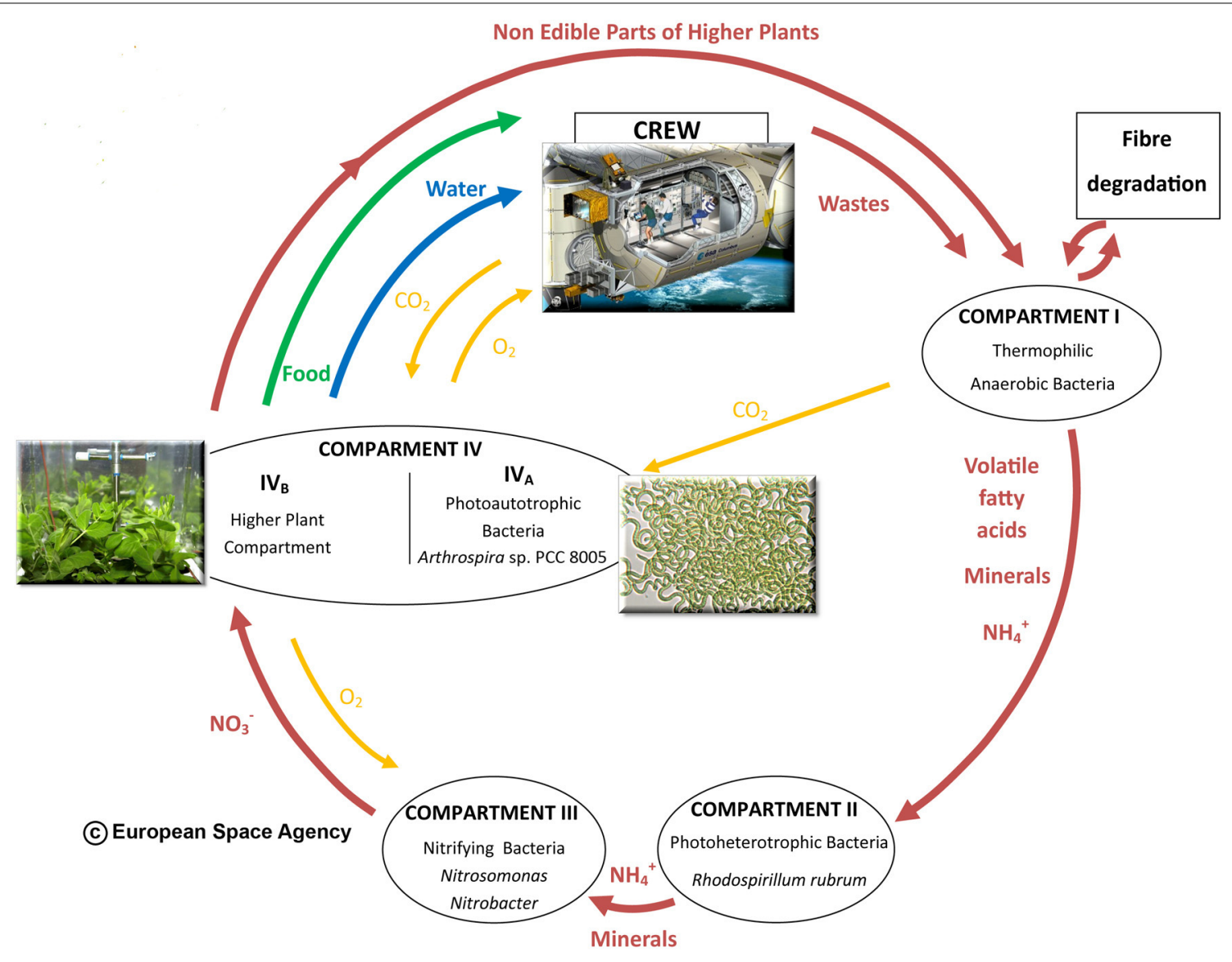

FIGURE 3 | Scheme presenting the four MELiSSA compartments for the recycling of organic waste into food, water, and oxygen.

high amounts of digestible proteins (50-70\% of biomass), betacarotene, omega- 6 fatty acids, phycocyanin, important minerals, and antioxidants (Koru, 2012). Marked activities of Arthrospira on human health include immunomodulation and anticancer, antiviral, and antibacterial activities while it has positive effects against inflammatory allergy, anemia, cytotoxicity, and radiation sickness (for full review see Ravi et al., 2010 and Sotiroudis and Sotiroudis, 2013).

It was recently shown that acute gamma radiation doses of up to $1600 \mathrm{~Gy}$ did not affect the photosynthetic capacity of Arthrospira as measured by PSII quantum yield and filaments proliferated normally (H. Badri, pers. comm.). This unexpected radiotolerance is reassuring in view of the relatively high radiation dose rates in Space $\left(0.2-1.2 \mathrm{mGy} \mathrm{d}^{-1}\right)$. However, the possibility of genetic changes induced in Arthrospira by chronic exposure to cosmic radiation cannot be excluded. The photosynthetic R. rubrum (which is in principle edible as well although it is not considered a primary food source in the MELiSSA concept) has previously been studied under real and simulated cosmic radiation and microgravity (Mastroleo et al., 2009). Similar work is now planned by the ESA for Arthrospira sp. PCC 8005 since its 2010 genome data (Janssen et al., 2010) have been very recently updated in an assembly of six ordered genome segments and a unique tiling microarray for all its genes has been constructed (P. Janssen, unpublished).
Clearly, bioregenerative life support systems such as MELiSSA show much promise, in particular when very high recycling efficiencies close to $100 \%$ can be achieved and taking into account that very few moving parts are used so that minimal maintenance is expected. The selection of the most hardy and most useful photosynthesisers, whether natural, purposely bred, or transgenic, is a challenge that can be met (Lehto et al., 2006; Saei et al., 2013). The only possible drawback of biological systems is that they are dynamic and that genetic changes induced by space conditions may lead to diminished functionality of the reactor loop. Hence, important issues for BLSS to be addressed in the near future are strict quality control, early warning mechanisms, guidelines for counter measures, and ultimately the ability of self-repair.

\section{CONCLUSIONS}

Space biology underlines the great potential that exists in the exploitation of the photosynthetic system since this addresses various aspects to produce food, including the recycling of materials and waste management for sustainability of life. Also, technological advances in green space research including lighting, hydroand aeroponic plant growth, vertical farming, and microbial purification of gray water are generally applicable to improve living conditions on earth. However, in order for such novel applications to make an impact on society, proper technology and knowledge transfer must be guaranteed. 
In addition, it will be important to address not just the quantitative aspect of production (e.g., higher yields) but also the qualitative side, sustaining a bio-based economy by also growing minor crops in environmental niches, the efficient use of resources, and an adequate input control. In the present era of climatic, economical, and societal changes, a better understanding of such a fundamental process as photosynthesis is expected to bring about important new technological and scientific initiatives.

Ideally, knowledge acquisition should drive sustainable, science-based innovation. In this, scientists must face their responsibility by communicating to the wider public that, for the development of a sustainable life, much can be learned and achieved by the keen observation of natural processes.

\section{ACKNOWLEDGMENTS}

The authors acknowledge the COST Action TD1102, Photosynthetic proteins for technological application: biosensors and biochips. COST (European Cooperation in Science and Technology) is Europe's longest-running intergovernmental framework for cooperation in science and technology funding cooperative scientific projects called 'COST Actions'. With a successful history of implementing scientific networking projects for over 40 years, COST offers scientists the opportunity to embark upon bottom-up, multidisciplinary and collaborative networks across all science and technology domains. For more information about COST, please visit www.cost.eu.

\section{REFERENCES}

Abbasi, T. and Abbasi, S. A. (2010). Biomass energy and the environmental impacts associated with its production and utilization. Renew. Sust. Energ. Rev. 14, 919-937. doi: 10.1016/j.res.2009.11.006

Abdi, F. F., Han, L., Smets, A. H. M., Zeman, M., Dam, B. and van de Krol, R. (2013). Efficient solar water splitting by enhanced charge separation in a bismuth vanadate-silicon tandem photoelectrode. Nat. Commun. 4:2195. doi: 10.1038/ncomms3195

Adenle, A. A., Haslam, G. E. and Lee, L. (2013). Global assessment of research and development for algae biofuel production and its potential role for sustainable development in developing countries. Energ. Policy 61, 182-195. doi: 10.1016/j.enpol.2013.05.088

Ajanovic, A. (2011). Biofuels versus food production: does biofuels production increase food prices? Energy 36, 2070-2076. doi: 10.1016/j.energy.2010.05.019

Ajayebi, A., Gnansounou, E. and Kenthorai Raman, J. (2013). Comparative life cycle assessment of biodiesel from algae and jatropha: a case study of India. Bioresour. Technol. 150, 429-437. doi: 10.1016/j.biortech.2013. 09.118

Allen, E., Browne, J., Hynes, S. and Murphy, J. D. (2013). The potential of algae blooms to produce renewable gaseous fuel. Waste Manag. 33, 2425-2433. doi: 10.1016/j.wasman.2013.06.017

An, J. Y., Sim, S. J., Lee, J. S. and Kim, B. K. (2003). Hydrocarbon production from secondarily treated piggery wastewater by the green algae, Botryococcus braunii. J. Appl. Phycol. 15, 185-191. doi: 10.1023/A:1023855710410

Ananyev, G., and Dismukes, G. C. (2005). How fast can photosystem II split water? Kinetic performance at high and low frequencies. Photosynth. Res. 84, 355-365. doi: 10.1007/s11120-004-7081-1

Andersson, I., and Backlund, A. (2008). Structure and function of Rubisco. Plant Physiol. Biochem. 46, 275-291. doi: 10.1016/j.plaphy.2008.01.001

Andreiadis, E. S., Chavarot-Kerlidou, M., Fontecave, M. and Artero, V. (2011). Artificial photosynthesis: from molecular catalysts for light-driven water splitting to photoelectrochemical cells. Photochem. Photobiol. 87, 946-964. doi: 10.1111/j.1751-1097.2011.00966.x

Anemaet, I. G., Bekker, M., and Hellingwerf, K. J. (2010). Algal photosynthesis as the primary driver for a sustainable development in energy, feed, and food production. Mar. Biotechnol. 12, 619-629. doi: 10.1007/s10126-010-9311-1
Aransiola, E. F., Ojumu, T. V., Oyekola, O. O., Madzimbamuto, T. F. and IkhuOmoregbe, D. I. O. (2014). A review of current technology for biodiesel production: state of the art. Biomass Bioenerg. 61, 276-297. doi: 10.1016/j. biombioe.2013.11.014

Aslan, S. and Kapdan, I. K. (2006). Batch kinetics of nitrogen and phosphorus removal from synthetic wastewater by algae. Ecol. Eng. 28, 64-70. doi: 10.1016/j.ecoleng.2006.04.003

Atkinson, B., and Mavituna, F. (1991). Biochemical Engineering and Biotechnology Handbook. 2nd Edn. New York, NY: Stockton Press.

Avinash, A., Subramaniam, D. and Murugesan, A. (2014), Bio-diesel - A global scenario. Renew. Sust. Energ. Rev. 29, 517-527. doi: 10.1016/j.rser.2013.09.007

Azapagic, A. (2014). Sustainability considerations for integrated biore?neries. Trends Biotechnol. 32, 1-4. doi: 10.1016/j.tibtech.2013.10.009

Badura, A., Esper, B., Ataka, K., Grunwald, C., Wöll, C., Kuhlmann, J. et al. (2006). Light-Driven water splitting for (Bio-)Hydrogen production: photosystem 2 as the central part of a bioelectrochemical device. Photochem. Photobiol. 82, 1385. doi: 10.1562/2006-07-14-RC-969

Bailey, J. V., (ed.). (1975). "Radiation protection and instrumentation," in NASASP-368, Biomedical Results of Apollo, Chapter 3, eds R. S. Johnson, L. F. Dietlein, C. A. Berry (Washington, DC: Publisher NASA Head Quarters), 105-115.

Barber, J. and Tran, P. D. (2013). From natural to artificial photosynthesis. J. R. Soc. Interface 10, 20120984. doi: 10.1098/rsif.2012.0984

Baturin, G. N. (2003). Phosphorous cycle in the ocean. Lithol. Mineral. Resour. 38, 101-119. doi: 10.1023/A:1023499908601

Beal, C., Hebner, R., Webber, M. E., Ruoff, R. S., Seibert, A. F., and King, C. W. (2012). Comprehensive evaluation of algal biofuel production: experimental and target results. Energies 5, 1943-1981. doi: 10.3390/en5061943

Benemann, J. R., Weissman, J. C., Koopman, B. L., and Oswald, W. J. (1977). Energy production by microbial photosynthesis. Nature 268, 19-23.

Bentley, F. K., Zurbriggen, A. and Melis, A. (2014). Heterologous expression of the mevalonic acid pathway in cyanobacteria enhances endogenous carbon partitioning to isoprene. Mol. Plant 7, 71-86. doi: 10.1093/mp/sst134

Benton, E. R., and Benton, E. V. (2001). Space radiation dosimetry in low-Earth orbit and beyond. Nuclear Instrum. Methods Phys. Res. B Beam Interact. Mater. Atoms 184, 255-294. doi: 10.1016/S0168-583X(01)00748-0

Berger, T., Hajek, M., Bilski, P., Körner, C., Vanhavere, F., and Reitz, G. (2012). Cosmic radiation exposure of biological test systems during the EXPOSE-E mission. Astrobiology 12, 387-392. doi: 10.1089/ast.2011.0777

Bhatnagar, S., and Kumari, R. (2013). Bioremediation: a sustainable tool for environmental management - a review. Ann. Rev. Res. Biol. 3, 974-993. Available online at: http://www.sciencedomain.org/download.php?f $=137620$ 1429-Bhatnagar342013ARRB5194.pdf\&aid $=1836$

Billi, D., Friedmann, E. I., Hofer, K. G., Caiola, M. G., and OcampoFriedmann, R. (2000). Ionizing-radiation resistance in the desiccation-tolerant cyanobacterium Chroococcidiopsis. Appl. Environ. Microbiol. 66, 1489-1492. doi: 10.1128/AEM.66.4.1489-1492.2000

Blankenship, R. E. and Chen, M. (2013). Spectral expansion and antenna reduction can enhance photosynthesis for energy production. Curr. Opin. Chem. Biol. 17, 457-461. doi: 10.1016/j.cbpa.2013.03.031

Blankenship, R. E., Tiede, D. M., Barber, J., Brudvig, G. W., Fleming, G., Ghirardi, M., et al. (2011). Comparing photosynthetic and photovoltaic efficiencies and recognizing the potential for improvement Science 332, 805-809. doi: $10.1126 /$ science. 1200165

Blatti, J. L., Michaud, J., and Burkart, M. D. (2013). Engineering fatty acid biosynthesis in microalgae for sustainable biodiesel. Curr. Opin. Chem. Biol. 17, 496-505. doi: 10.1016/j.cbpa.2013.04.007

Blüm, V. (1992). CEBAS, a closed equilibrated biological aquatic system as a possible precursor for a long-term life support system?. Adv. Space Res. 12, 193-204. doi: 10.1016/0273-1177(92)90024-R

Blüm, V., Andriske, M., Ludwig, C., Paaßen, U., and Voeste, D. (2003). The "CEBAS mini-module": a self-sustaining closed aquatic ecosystem for spaceflight experimentation. Adv. Space Res. 31, 201-210. doi: 10.1016/S0273-1177(02)00750-0

Borowitzka, M. A. and Moheimani, N. R. (2013). Sustainable biofuels from algae. Mitig. Adapt. Strat. Gl. Change 18, 13-25. doi: 10.1007/s11027-010-9271-9

Brabec, C. J., Gowrisanker, S., Halls, J. J. M., Laird, D., Jia, S. and Williams, S. P. (2010). Polymer Fullerene bulk-heterojunction solar cells. Adv. Mater. 22, 3839-3856. doi: 10.1002/adma.200903697

Brennan, L. and Owende, P. (2013). "Biofuels from microalgae: towards meeting advanced fuel standards," in Advanced Biofuels and Bioproducts, ed J. W. Lee 
(New York, NY: Springer Science+Business Media), 553-599. doi: 10.1007/9781-4614-3348-4_24

Buijs, N. A., Siewers, V. and Nielsen, J. (2013). Advanced biofuel production by the yeast Saccharomyces cerevisiae. Curr. Opin. Chem. Biol. 17, 480-488. doi: 10.1016/j.cbpa.2013.03.036

Buonasera, K., Pezzotti, G., Scognamiglio, V., Tibuzzi, A., and Giardi, M. T. (2009). New platform of biosensors for prescreening of pesticide residues to support laboratory analyses. J. Agric. Food Chem. 58, 5982-5990. doi: 10.1021/jf9027602

Burschka, J., Pellet, N., Moon, S., Humphry-Baker, R., Gao, P., Nazeeruddin, M. K. et al. (2013). Sequential deposition as a route to high-performance perovskitesensitized solar cells. Nature 499, 316-319. doi: 10.1038/nature12340

Carmo-Silva, A. E., and Salvucci, M. E. (2012). The temperature response of $\mathrm{CO}_{2}$ assimilation, photochemical activities and Rubisco activation in Camelina sativa, a potential bioenergy crop with limited capacity for acclimation to heat stress. Planta 236, 1433-1445. doi: 10.1007/s00425-012-1691-1

Carvalho, J., Madgwick, P., Powers, S., Keys, A., Lea, P., and Parry, M. (2011). An engineered pathway for glyoxylate metabolism in tobacco plants aimed to avoid the release of ammonia in photorespiration. BMC Biotechnol. 11:111. doi: 10.1186/1472-6750-11-111

Casado, J. (2006). "Horticulture in space" in Spaceflight-The Magazine of Astronautics and Outer Space. London: British Interplanetary Society.

Chacón-Lee, T. L., and González-Mariño, G. E. (2010). Microalgae for "healthy" foods-possibilities and challenges. Compr. Rev. Food Sci. Food Safety 9, 655-675. doi: 10.1111/j.1541-4337.2010.00132

Chaves, A. L. S., and Mello-Farias, P. C. D. (2006). Ethylene and fruit ripening: from illumination gas to the control of gene expression, more than a century of discoveries. Genet. Mol. Biol.29, 508-515. doi: 10.1590/S1415-47572006000300020

Chen, C. Y., Yeh, K. L., Aisyah, R., Lee, D. J. and Chang, J. S. (2011). Cultivation, photobioreactor design and harvesting of microalgae for biodiesel production: a critical review. Bioresour. Technol. 102, 71-81. doi: 10.1016/j.biortech. 2010.06.159

Cheng, J., Huang, R., Yu, T., Li, T., Zhou, J., and Cen, K. (2014). Biodiesel production from lipids in wet microalgae with microwave irradiation and bio-crude production from algal residue through hydrothermal liquefaction. Bioresour. Technol. 151, 415-418. doi: 10.1016/j.biortech.2013.10.033

Chen, M., and Blankenship, R. E. (2011). Expanding the solar spectrum used by photosynthesis. Trends Plant Sci. 16, 427-431. doi: 10.1016/j.tplants.2011. 03.011

Chen, M., Schliep, M., Willows, R. D., Cai, Z. L., Neilan. B. A., and Scheer, H. (2010). A red-shifted chlorophyll. Science 329, 1318-1319. doi: 10.1126/science. 1191127

Chen, W. T., Zhang, Y., Zhang, J., Yu, G., Schideman, L. C., Zhang, P., and Minarick, M. (2014). Hydrothermal liquefaction of mixed-culture algal biomass from wastewater treatment system into bio-crude oil. Bioresour. Technol. 152, 130-139. doi: 10.1016/j.biortech.2013.10.111

Chiaiese, P., Palomba, F., Tatino, F., Lanzillo, C., Pinto, G., Pollio, A., and Filippone, E. (2011). Engineered tobacco and microalgae secreting the fungal laccase POXA1b reduce phenol content in olive oil mill wastewater. Enzyme Microb. Technol. 49, 540-546. doi: 10.1016/j.enzmictec.2011.06.002

Chinnasamy, S., Bhatnagar, A., Hunt, R. W. and Das, K. C. (2010). Microalgae cultivation in a wastewater dominated by carpet mill effluents for biofuel applications. Bioresour. Technol. 101, 3097-3105. doi: 10.1016/j.biortech.2009.12.026

Chiu, S. Y., Kao, C. Y., Huang, T. T., Lin, C. J., Ong, S. C., Chen, C. D., et al. (2011). Microalgal biomass production and on-site bioremediation of carbon dioxide, nitrogen oxide and sulfur dioxide from flue gas using Chlorella sp. Cultures. Bioresour. Technol. 102, 9135-9142. doi: 10.1016/j.biortech.2011. 06.091

Christians, J. A., Fung, R. C., and Kamat, P. V. (2014). An inorganic hole conductor for organo-lead halide perovskite solar cells. Improved hole conductivity with copper iodide. J. Amer. Chem. Soc. 136, 758-764. doi: 10.1021/ja411014k

Choi, Y. J., and Lee, S. Y. (2013). Microbial production of short-chain alkanes. Nature 502, 571-574. doi: 10.1038/nature 12536

Clay, S. M. and Fong, S. S. (2013). "Life Cycle Assessment," in Developing Biofuel Bioprocesses Using Systems and Synthetic Biology, eds S. M. Clay and S. S. Fong (New York, NY: Springer), 15-17. doi: 10.1007/978-1-4614-5580-6_3

Cockell, C. S., Rettberg, P., Rabbow, E., and Olsson-Francis, K. (2011). Exposure of phototrophs to 548 days in low earth orbit: microbial selection pressures in outer space and on early earth. ISME J. 5, 1671-1682. doi: 10.1038/ismej. 2011.46
Correll, D. L. (1998). The role of phosphorus in the eutrophication of receiving waters: a review. J. Environ. Q. 27, 261-266. doi: 10.2134/jeq1998.00472425002 $700020004 \mathrm{x}$

da Silva, T. L., Gouveia, L., and Reis, A. (2013). Integrated microbial processes for biofuels and high value-added products: the way to improve the cost effectiveness of biofuel production. Appl. Microbiol. Biotechnol. 98, 1043. doi: 10.1007/s00253-013-5389-5

Das, R., Kiley, P. J., Segal, M., Norville, J., Yu, A. A., Wang, L. et al. (2004). Integration of photosynthetic protein molecular complexes in solid-state electronic devices. Nano. Lett. 4, 1079-1083. doi: 10.1021/nl049579f

de-Bashan, L. E., and Bashan, Y. (2010). Immobilized microalgae for removing pollutants: review of practical aspects. Bioresour. Technol. 101, 1611-1627. doi: 10.1016/j.biortech.2009.09.043

De Philippis, R., Colica, G., and Micheletti, E. (2011). Exopolysaccharideproducing cyanobacteria in heavy metal removal from water: molecular basis and practical applicability of the biosorption process. Appl. Microbiol. Biotechnol. 92, 697-708. doi: 10.1007/s00253-011-3601-z

Fahti, A. A., Azooz, M. M., and Al-Fredan, M. A. (2013). Phycoremediation and the potential of sustainable algal biofuel production using watewater. Am. J. Appl. Sci. 10, 189-194. doi: 10.3844/ajassp.2013.189.194

Fedoroff, N. V., Battisti, D. S., Beachy, R. N., Cooper, P. J. M., Fischhoff, D. A., Hodges, C. N., et al. (2010). Radically rethinking agriculture in the 21 st century. Science 327, 883-884. doi: 10.1126/science.1186834

Freeman, M. (1998). Research on mir advances growing plants in space. EIR Science Technol. 25, 26-35.

Frischmann, P. D., Mahata, K., and Wurthner, F. (2013). Powering the future of molecular artificial photosynthesis with light-harvesting metallosupramolecular dye assemblies. Chem. Soc. Rev. 42, 1847. doi: 10.1039/C2CS35223K

Frölicher, T. L., and Joos, F. (2010). Reversible and irreversible impacts of greenhouse gas emissions in multi-century projections with the NCAR global coupled carbon cycle-climate model. Climate Dynam. 35, 1439-1459. doi: 10.1007/s00382-009-0727-0

Fu, F. and Wang, Q. (2011). Removal of heavy metal ions from wastewaters: a review. J. Environ. Manage. 92, 407-418. doi: 10.1016/j.jenvman.2010.11.011

Fukuda, S. Y., Iwamoto, K., Atsumi, M., Yokoyama, A., Nakayama, T., Ishida, K., et al. (2014). Global searches for microalgae and aquatic plants that can eliminate radioactive cesium, iodine and strontium from the radio-polluted aquatic environment: a bioremediation strategy. J. Plant Res. 127, 79-89. doi: 10.1007/s10265-013-0596-9

Gallagher, C., and Murphy, J. D. (2013). Is it better to produce biomethane via thermochemical or biological routes? An energy balance perspective. Biofuels Bioprod. Bior. 7, 273-281. doi: 10.1002/bbb.1390

Ge, Y., Liu, J., and Tian, G. (2011). Growth characteristics of Botryococcus braunii 765 under high $\mathrm{CO}_{2}$ concentration in photobioreactor. Bioresour. Technol. 102, 130-134. doi: 10.1016/j.biortech.2010.06.051

Genkov, T., Meyer, M., Griffiths, H., and Spreitzer, R. J. (2010). Functional hybrid rubisco enzymes with plant small subunits and algal large subunits. Engineered rbcS cDNA for expression in Chlamydomonas. J. Biol. Chem. 285, 19833-19841. doi: 10.1074/jbc.M110.124230

Gerster, D., Reichert, J., Bi, H., Barth, J. V., Kaniber, S. M., Holleitner, A. W. et al. (2012). Photocurrent of a single photosynthetic protein. Nat. Nanot. 7, 673-676. doi: $10.1038 /$ nnano.2012.165

Ghasemi, Y., Rasoul-Amini, S. and Fotooh-Abadi, E. (2011). The biotransformation, biodegradation, and bioremediation of organic compounds by microalgae. J. Phycol. 47, 969-980. doi: 10.1111/j.1529-8817.2011.01051.x

Ghasemi, Y., Rasoul-Amini, S., Naseri, A. T., Montazeri-Najafabady, N., Mobasher, M. A. and Dabbagh, F. (2012). Microalgae biofuel potentials. Prikl. Biokhim. Mikrobiol. 48, 150-168. doi: 10.1134/S0003683812020068

Gimpel, J. A., Specht, E. A., Georgianna, D. R., and Mayfield, S. P. (2013). Advances in microalgae engineering and synthetic biology applications for biofuel production. Curr. Opin. Chem. Biol. 17, 489-495. doi: 10.1016/j.cbpa.2013. 03.038

Gitelson, I. I., Terskov, I. A., Kovrov, B. G., Lisovskii, G. M., Okladnikov, Y. N., Sid'Ko, F. Y., et al. (1989). Long-term experiments on man's stay in biological life-support system. Adv. Space Res. 9, 65-71. doi: 10.1016/0273-1177(89) 90030-6

González, R., García-Balboa, C., Rouco, M., Lopez-Rodas, V. and Costas, E. (2012). Adaptation of microalgae to lindane: a new approach for bioremediation. Aquat. Toxicol. 109, 25-32. doi: 10.1016/j.aquatox.2011.11.015 
Goossens, O., Vanhavere, F., Leys, N., De Boever, P., O'sullivan, D., Zhou, D., et al. (2006). Radiation dosimetry for microbial experiments in the International space station using different etched track and luminescent detectors. Radiat. Prot. Dosimetry 120, 433-437. doi: 10.1093/rpd/nci652

Gosh, M., and Singh, S. P. (2005). A review on phytoremediation of heavy metal and utilization of its byproducts. Appl. Ecol. Environ. Res. 3, 1-18. Available online at: www.ecology.kee.hu/pdf/0301_001018.pdf

Grätzel, M. (1991). The artificial leaf, molecular photovoltaics achieve efficient generation of electricity from Sunlight. Comments Inorg. Chem. 12, 93-111. doi: 10.1080/02603599108050599

Greenwell, H. C., Laurens, L. M., Shields, R. J., Lovitt, R. W., and Flynn, K. J. (2010). Placing microalgae on the biofuels priority list: a review of the technological challenges J. R. Soc. Interface 7, 703-726. doi: 10.1098/rsif.2009.0322

Grimme, R. A., Lubner, C. E., Bryant, D. A. and Golbeck, J. H. (2008). Photosystem I/Molecular Wire/Metal nanoparticle bioconjugates for the photocatalytic production of $\mathrm{H}_{2}$. J. Am. Chem. Soc. 130, 6308-6309. doi: 10.1021/ja800923y

Gronenberg, L. S., Marcheschi, R. J. and Liao, J. C. (2013). Next generation biofuel engineering in prokaryotes. Curr. Opin. Chem. Biol. 17, 462-471. doi: 10.1016/j.cbpa.2013.03.037

Gu, J., Yin, X., Stomph, T.-J., and Struick, P. C. (2014). Can exploiting natural genetic variation in leaf photosynthesis contribute to increasing rice productivity? A simulation analysis. Plant Cell Environ. 37, 22-34. doi: 10.1111/pce.12173

Halim, R., Danquah, M. K. and Webley, P. A. (2012). Extraction of oil from microalgae for biodiesel production: a review. Biotechnol. Adv. 30, 709-732. doi: 10.1016/j.biotechadv.2012.01.001

Hannon, M., Gimpel, J., Tran, M., Rasala, B., and Mayfield, S. (2011). Biofuels from algae: challenges and potential. Biofuels 1, 763-784. doi: 10.4155/bfs.10.44

Hartmann, V., Kothe, T., Pöller, S., El-Mohsnawy, E., Nowaczyk, M. M., Plumeré, N., et al. (2014). Redox hydrogels with adjusted redox potential for improved efficiency in Z-scheme inspired biophotovoltaic cells. Phys. Chem. Chem. Phys. 16, 11936-11941. doi: 10.1039/C4CP00380B

Hassler, D. M., Zeitlin, C., Wimmer-Schweingruber, R. F., Ehresmann, B., Rafkin, S., Eigenbrode, J. L., and Newcombe, M. (2014). Mars' Surface radiation environment measured with the Mars Science laboratory's curiosity rover. Science 343, 1244797. doi: 10.1126/science. 1244797

Hazrat, A., Ezzat, K., and Muhammad, A. S. (2013). Phytoremediation of heavy metals-concepts and applications. Chemosphere 91, 869-881. doi: 10.1016/j. chemosphere.2013.01.075

Hendrickx, L., and Mergeay, M. (2007). From the deep sea to the stars: human life support through minimal communities. Curr. Opin. Microbiol. 10, 231-237. doi: 10.1016/j.mib.2007.05.007

Hendrickx, L., De Wever, H., Hermans, V., Mastroleo, F., Morin, N., Wilmotte, A., and Mergeay, M. (2006). Microbial ecology of the closed artificial ecosystem MELiSSA (Micro-Ecological Life Support System Alternative): reinventing and compartmentalizing the Earth's food and oxygen regeneration system for long-haul space exploration missions. Res. Microbiol. 157, 77-86. doi: 10.1016/j.resmic.2005.06.014

Hoffmann, J. P. (1998). Wastewater treatment with suspended and nonsuspended algae. J. Phycol. 34, 757-763. doi: 10.1046/j.1529-8817.1998.340757.x

Ibraheem, I. B. M. (2010). Biodegradability of hydrocarbons by cyanobacteria. J. Phycol. 46, 818-824. doi: 10.1111/j.1529-8817.2010.00865.x

Ihara, M., Nishihara, H., Yoon, K., Lenz, O., Friedrich, B., Nakamoto, H. et al. (2006). Light-driven hydrogen production by a hybrid complex of a [NiFe]hydrogenase and the cyanobacterial photosystem I. Photochem. Photobiol. 82, 676-682. doi: 10.1562/2006-01-16-RA-778

Irmak, S., Kurtulus, M., Hasanoglu (Hesenov), A., and Erbatur, O. (2013). Gasification efficiencies of cellulose, hemicelluloses and lignin fractions of biomass in aqueous media by using $\mathrm{Pt}$ on activated carbon catalyst. Biomass Bioenerg. 49, 102-108. doi: 10.1016/j.biombioe.2012.12.016

Ishikawa, C., Hatanaka, T., Misoo, S., Miyake, C., and Fukayama, H. (2011). Functional incorporation of sorghum small subunit increases the catalytic turnover rate of Rubisco in transgenic rice. Plant Physiol. 156, 1603-1611. doi: 10.1104/pp.111.177030

Ivanova, T. N., Bercovich, Y. A., Mashinskiy, A. L., and Meleshko, G. I. (1993). The first "space" vegetables have been grown in the "SVET" greenhouse using controlled environmental conditions. Acta Astronautica 29, 639-644. doi: 10.1016/0094-5765(93)90082-8

Ivanova, T. N., Kostov, P. T., Sapunova, S. M., Dandolov, I. W., Salisbury, F. B., Bingham, G. E., et al. (1998). Six-month space greenhouse experiments-a step to creation of future biological life support systems. Acta astronautica 42, 11-23. doi: 10.1016/S0094-5765(98)00102-7

Iwuchukwu, I. J., Vaughn, M., Myers, N., O’Neill, H., Frymier, P., and Bruce, B. D. (2009). Self-organized photosynthetic nanoparticle for cellfree hydrogen production. Nat. Nanotech. 5, 73-79. doi: 10.1038/nnano. 2009.315

Janssen, P., Morin, N., Valleys, T., Tandeau de Marsac, N., Leys, N., Talla, H., et al. (2010). Genome sequence of the edible Cyanobacterium Arthrospira sp. PCC 8005. J. Bacteriol. 192, 2465-2466. doi: 10.1128/JB.00116-10

Jarda, G., Marfaing, H., Carrère, H., Delgenes, J. P., Steyer, J. P. and Dumas, C. (2013). French Brittany macroalgae screening: composition and methane potential for potential alternative sources of energy and products. Bioresour. Technol. 144, 492-498. doi: 10.1016/j.biortech.2013.06.114

Jimenez-Perez, M. V., Sanches-Castillo, P., Romera, O., Fernandez-Moreno, D. and Perez-Martinez, C. (2004). Growth and nutrient removal in free and immobilized planktonic green algae isolated from pig manure. Enzyme Microb. Technol. 34, 392-398. doi: 10.1016/j.enzmictec.2003.07.010

Jin, J., Huang, W., Gao, J.-P., Yang, J., Shi, M., Zhu, M.-Z., et al. (2008). Genetic control of rice plant architecture under domestication. Nat. Gen. 40, 1365-1369. doi: $10.1038 / \mathrm{ng} .247$

Jin, Z. P., Luo, K., Zhang, S., Zheng, Q. and Yang, H. (2012). Bioaccumulation and catabolism of prometryne in green algae. Chemosphere 87, 278-284. doi: 10.1016/j.chemosphere.2011.12.071

Kajala, K., Covshoff, S., Karki, S., Woodfield, H., Tolley, B. J., Dionora, M. J., et al. (2011). Strategies for engineering a two-celled C4 photosynthetic pathway into rice. J. Exp. Bot. 62, 3001-3010. doi: 10.1093/jxb/err022

Karki, S., Rizal, G., and Quick, W. P. (2013). Improvement of photosynthesis in rice (Oryza sativa L.) by inserting the C4 pathway. Rice 6, 28. doi: 10.1186/19398433-6-28

Kebeish, R., Niessen, M., Thiruveedhi, K., Bari, R., Hirsch, H.-J., Rosenkranz, R., et al. (2007). Chloroplastic photorespiratory bypass increases photosynthesis and biomass production in Arabidopsis thaliana. Nat. Biotech. 25, 593-599. doi: $10.1038 /$ nbt1299

Kendall, A. and Yuan, J. (2013). Comparing life cycle assessments of different biofuel options. Curr. Opin. Chem. Biol. 17, 439-443. doi: 10.1016/j.cbpa.2013. 02.020

Kirst, H., Garcia-Cerdan, J. G., Zurbriggen, A., Ruehle, T., and Melis, A. (2012). Truncated photosystem chlorophyll antenna size in the green microalga Chlamydomonas reinhardtii upon deletion of the TLA3-CpSRP43 gene. Plant Physiol. 160, 2251-2260. doi: 10.1104/pp.112.206672

Kiss, J. Z. (2014). Plant biology in reduced gravity on the Moon and Mars. Plant Biol. 16, 12-17. doi: 10.1111/plb.12031

Koçar, G. and Civaş, N. (2013). An overview of biofuels from energy crops: current status and future prospects. Renew. Sust. Energ. Rev. 28, 900-916. doi: 10.1016/j.rser.2013.08.022

Kolesinski, P., Golik, P., Grudnik, P., Piechota, J., Markiewicz, M., Tarnawski, M., et al. (2013). Insights into eukaryotic Rubisco assembly - Crystal structures of RbcX chaperones from Arabidopsis thaliana. Biochim. Biophys. Acta 1830, 2899-2906. doi: 10.1016/j.bbagen.2012.12.025

Kong, Q. X., Li, L., Martinez, B., Chen, P., and Ruan, R. (2010). Culture of microalgae Chlamydomonas reinhardtii in wastewater for biomass feedstock production. Appl. Biochem. Biotechnol. 160, 9-18. doi: 10.1007/s12010-0098670-4

Kopetz, H. (2013). Renewable resources: build a biomass energy market. Nature 494, 29-31. doi: 10.1038/494029a

Koru, E. (2012). "Earth food spirulina (Arthrospira): production and quality standarts, in food additive," in In Tech, ed Y. El-Samragy, 191-202.

Kothe, T., Plumeré, N., Badura, A., Nowaczyk, M. M., Guschin, D. A., and Rögner, M. et al. (2013a). Combination of a photosystem 1-Based photocathode and a photosystem 2-based photoanode to a Z-Scheme mimic for biophotovoltaic applications. Angew. Chem. Int. Ed. 52, 14233-14236. doi: 10.1002/anie.201303671

Kothe, T., Plumeré, N., Badura, A., Nowaczyk, M. M., Guschin, D. A., and Rögner, M. et al. (2013b). Die Kombination einer auf Photosystem 1 basierenden Photokathode und einer auf Photosystem 2 basierenden Photoanode zu einem Z-Schema-Analogon für biophotovoltaische Anwendungen. Angew. Chem. 125, 14483-14486. doi: 10.1002/ange.201303671

Kothe, T., Pöller, S., Zhao, F., Fortgang, P., Rögner, M., Schuhmann, W., and Plumeré, N. (2014). Engineered electron transfer chain in Photosystem 1 based 
photocathodes outperforms electron transfer rates in natural photosynthesis. Chem. Eur. J. doi: 10.1002/chem.201402585

Kovarik, B. (2013). "Biofuels in history," in Biofuel Crops: Production, Physiology and Genetics, ed B. P. Singh (Wallingford, UK: CABI Publishing), 1-22. doi: 10.1079/9781845938857.0001

Krassen, H., Schwarze, A., Friedrich, B., Ataka, K., Lenz, O. and Heberle, J. (2009). Photosynthetic Hydrogen production by a hybrid complex of photosystem I and [NiFe]-Hydrogenase. ACS Nano 3, 4055-4061. doi: 10.1021/nn9 $00748 j$

Krejci, M. R., Finney, L., Vogt, S., and Joester, D. (2011). Selective sequestration of strontium in desmid green algae by biogenic co-precipitation with barite. ChemSusChem 4, 470-473. doi: 10.1002/cssc.201000448

Kruse, A., Funke, A. and Titirici, M. M. (2013). Hydrothermal conversion of biomass to fuels and energetic materials. Curr. Opin. Chem. Biol. 17, 515-521. doi: 10.1016/j.cbpa.2013.05.004

Kumar, A., Li, C., and Portis, A. R. Jr. (2009). Arabidopsis thaliana expressing a thermostable chimeric Rubisco activase exhibits enhanced growth and higher rates of photosynthesis at moderately high temperatures. Photosynth. Res. 100, 143-153. doi: 10.1007/s11120-009-9438-y

Langdale, J. A. (2011). C4cycles: past, present, and future research on C4 photosynthesis. Plant Cell. 23, 3879-3892. doi: 10.1105/tpc.111.092098

Lambreva, M. D., Giardi, M. T., Rambaldi, I., Antonacci, A., Pastorelli, S., Bertalan, I., et al. (2013). A powerful molecular engineering tool provided efficient chlamydomonas mutants as bio-sensing elements for herbicides detection. PLoS ONE 8:e61851. doi: 10.1371/journal.pone.0061851

Larkum, A. W., Ross, I. L., Kruse, O. and Hankamer, B. (2012). Selection, breeding and engineering of microalgae for bioenergy and biofuel production. Trends Biotechnol. 30, 198-205. doi: 10.1016/j.tibtech.2011.11.003

Lasseur, C., Brunet, J., de Weever, H., Dixon, M., Dussap, G., Godia, F., and Van Der Straeten, D. (2011). MELiSSA: the European project of closed life support system. Gravit. Space Res. 23. Available online at: http://gravitationalandspacebiology.org/index.php/journal/article/view/487

Lee, K., and Lee, C. G. (2001). Effect of light/dark cycles on wastewater treatments by microalgae. Biotechnol. Bioprocess Engg. 6, 194-199. doi: 10.1007/BF02932550

Lee, R. A. and Lavoie, J. M. (2013). From first- to third-generation biofuels: challenges of producing a commodity from a biomass of increasing complexity. Anim. Front. 3, 6-11. doi: 10.2527/af.2013-0010

Leegood, R. C. (2013). Strategies for engineering C4 photosynthesis. J. Plant Physiol. 170, 378-388. doi: 10.1016/j.jplph.2012.10.011

Lehto, K. M., Lehto, H. J., and Kanervo, E. A. (2006). Suitability of different photosynthetic organisms for an extraterrestrial biological life support system. Res. Microbiol. 157, 69-76. doi: 10.1016/j.resmic.2005.07.011

Leite, G. B., and Hallenbeck, P. C. (2014). "Engineered cyanobacteria: research and application in bioenergy," in Bioenergy Research: Advances and Applications, eds V. K. Gupta, C. P. Kubicek, J. Saddler, F. Xu, and M. G. Tuohy (Oxford, UK: Elsevier). doi: 10.1016/B978-0-444-59561-4.00022-X

Li, H., Liu, Z., Zhang, Y., Li, B., Lu, H., Duan, N., et al. (2014). Conversion efficiency and oil quality of low-lipid high-protein and high-lipid low-protein microalgae via hydrothermal liquefaction. Bioresour. Technol. 154, 322-329. doi: 10.1016/j.biortech.2013.12.074

Li, Y., Horsman, M., Wu, N., Lan, C. Q. and Dubois-Calero, N. (2008). Biofuels from microalgae. Biotechnol. Prog. 24, 815-820. doi: 10.1021/bp070371k

Liang, Y., Xu, Z., Xia, J., Tsai, S., Wu, Y., Li, G. et al. (2010). For the bright futurebulk heterojunction polymer solar cells with power conversion efficiency of 7.4\%. Adv. Mater. 22, E135. doi: 10.1002/adma.200903528

Liberton, M., Collins, A. M., Page, L. E., O’Dell, W. B., O'Neill, H., Urban, V. S., et al. (2013). Probing the consequences of antenna modification in cyanobacteria. Photosynth. Res. 118, 17-24. doi: 10.1007/s11120-013-9940-0

Liew, W. H., Hassim, M. H., and Ng, D. K. S. (2014). Review of evolution, technology and sustainability assessments of biofuel production. J. Clean. Prod. 72, 46-56. doi: 10.1016/j.jclepro.2014.01.006

Lim, S. L., Chu, W. L. and Phang, S. M. (2010). Use of Chlorella vulgaris for bioremediation of textile wastewater. Bioresour. Technol. 101, 7314-7322. doi: 10.1016/j.biortech.2010.04.092

Liu, C., Young, A. L., Starling-Windhof, A., Bracher, A., Saschenbrecker, S., Rao, B. V., et al. (2010). Coupled chaperone action in folding and assembly of hexadecameric Rubisco. Nature 463, 197-202. doi: 10.1038/ nature 08651
Lone, M. I., He, Z., Stoffella, P. J., and Yang, Y. (2008). Phytoremediation of heavy metal polluted soils and water: progresses and perspectives. J. Zheijang Univ. Sci. B. 9, 210-220. doi: 10.1631/jzus.B0710633

Long, S. P. (2014). We need winners in the race to increase photosynthesis in rice, whether from conventional breeding, biotechnology or both. Plant Cell Environ. 37, 19-21. doi: 10.1111/pce.12193

Lü, J., Sheahan, C. and Fu, P. (2011). Metabolic engineering of algae for fourth generation biofuels production. Energ. Environ. Sci. 4, 2451-2466. doi: 10.1039/C0EE00593B

Maier, A., Fahnenstich, H., Von Caemmerer, S., Engqvist, M. K., Weber, A. P. M., Flugge, U.-I., et al. (2012). Transgenic introduction of a glycolate oxidative cycle into A. thaliana chloroplasts leads to growth improvement. Front. Plant Sci. 3:38. doi: 10.3389 /fpls.2012.00038

Makareviciene, V., Skorupskaite, V. and Andruleviciute, V. (2013). Biodiesel fuel from microalgae-promising alternative fuel for the future: a review. Rev. Environ. Sci. Biotechnol. 2, 119-130. doi: 10.1007/s11157-013-9312-4

Maliga, P., and Bock, R. (2011). Plastid biotechnology: food, fuel, and medicine for the 21st century. Plant Physiol. 155, 1501-1510. doi: 10.1104/pp.110.170969

Mallick, N. (2002). Biotechnological potential of immobilized algae for wastewater N, P and metal removal: a review. Biometals 15, 377-390. doi: 10.1023/A:1020238520948

Marmiroli, N., Marmiroli, M., and Maestri, E. (2006). "Phytoremediation and Phytotechnologies: a review for the present and the future," in NATO Science Series Vol. 69. Soil and Water Pollution Monitoring, Protection and Remediation, eds I. Twardowska, H. E. Allen, M. M. Häggblom, S., and N. A. Stefaniak (Dordrecht: Springer), 403-416. doi: 10.1007/978-1-4020-4728-2_26

Martínez, M. E., Sánchez, S., Jiménez, J. M., El Yousfi, F. and Munoz, L. (2000). Nitrogen and phosphorus removal from urban wastewater by the microalga Scenedesmus obliquus. Bioresour. Technol. 73, 263-272. doi: 10.1016/S09608524(99)00121-2

Mashinsky, A., Ivanova, I., Derendyaeva, T., Nechitailo, G., and Salisbury, F. (1994). "From seed-to-seed" experiment with wheat plants under space-flight conditions. Adv. Space Res. 14, 13-19. doi: 10.1016/0273-1177(94)90274-7

Massa, G. D., Emmerich, J. C., Morrow, R. C., Bourget, C. M., and Mitchell, C. A. (2006). Plant-growth lighting for space life support: a review. Gravit. Space Res. 19, 19-30. Available online at: http://gravitationalandspacebiology.org/ index.php/journal/article/download/2/2?origin=publication_detail

Mastroleo, F., Van Houdt, R., Leroy, B., Benotmane, M. A., Janssen, A., Mergeay, M., et al. (2009). Experimental design and environmental parameters affect Rhodospirillum rubrum S1H response to space flight. ISME J. 3, 1402-1419. doi: 10.1038 /ismej.2009.74

Maza-Márquez, P., Martinez-Toledo, M. V., Fenice, L., Andrade, M., Lasse rrot, A., and Gonzalez-Lopez, J. (2014). Biotreatment of olive washing wastewater by a selected microalgal-bacterial consortium. Int. Biodeter. Biodegr. 88, 69-76. doi: 10.1016/j.ibiod.2013.12.009

McGinn, P. J., Dickinson, K. E., Bhatti, S., Frigon, J. C., Guiot, S. R., and O'Leary, S. J. (2011). Integration of microalgae cultivation with industrial waste remediation for biofuel and bioenergy production: opportunities and limitations. Photosyn. Res. 109, 231-247. doi: 10.1007/s11120-0119638-0

Megiatto, J. D., Antoniuk-Pablant, A., Sherman, B. D., Kodis, G., Gervaldo, M., Moore, T. A. et al. (2012). Mimicking the electron transfer chain in photosystem II with a molecular triad thermodynamically capable of water oxidation. Proc. Natl. Acad. Sci. 109, 15578-15583. doi: 10.1073/pnas. 1118348109

Mehta, S. K., and Gaur, J. P. (2005). Use of algae for removing heavy metal ions from wastewater: progress and prospects. Crit. Rev. Biotechnol. 25, 113-152. doi: $10.1080 / 07388550500248571$

Melis, A. (2013). Carbon partitioning in photosynthesis. Curr. Opin. Chem. Biol. 17, 453-456. doi: 10.1016/j.cbpa.2013.03.010

Mendez, M., Behnke, C., Poon, Y., and Lee, P. (2009). Induction of floculation in photosynthetic organisms. U.S. Patent Application 13/001,027.

Menetrez, M. Y. (2012). An overview of algae biofuel production and potential environmental impact. Environ. Sci. Technol. 46, 7073-7085. doi: $10.1021 /$ es $300917 \mathrm{r}$

Mergeay, M., Verstraete, W., Dubertret, G., Lefort-Tran, M., Chipaux, C., and Binot, R. A. (1988). "MELiSSA: a microorganisms-based model for CELLS development," in Proceedings of the 3rd Symposium on Space Thermal Control and Life Support Systems (Noordwijk), 65-68. 
Mershin, A., Matsumoto, K., Kaiser, L., Yu, D., Vaughn, M., Nazeeruddin, M. K. et al. (2012). Self-assembled photosystem-I biophotovoltaics on nanostructured TiO2 and ZnO. Sci. Rep. 2:234. doi: 10.1038/srep00234

Meyer, M., and Griffiths, H. (2013). Origins and diversity of eukaryotic $\mathrm{CO}_{2}-$ concentrating mechanisms: lessons for the future. J. Exp. Bot. 64, 769-786. doi: 10.1093/jxb/ers390

Mielke, S. P., Kiang, N. Y., Blankenship, R. E., and Mauzerall, D. (2013). Photosystem trap energies and spectrally-dep'nt energy-storage efficiencies in the Chl d-utilizing cyanobacterium, Acaryochloris marina. Biochim. Biophys. Acta. 1827, 255-265. doi: 10.1016/j.bbabio.2012.11.002

Millar, K. D., Kumar, P., Correll, M. J., Mullen, J. L., Hangarter, R. P., Edelmann, R. E., et al. (2010). A novel phototropic response to red light is revealed in microgravity. New Phytol. 186, 648-656. doi: 10.1111/j.1469-8137.2010.03211.x

Miller, S. R., McGuirl, M. A., and Carvey, D. (2013). The evolution of RuBisCO stability at the thermal limit of photoautotrophy. Mol. Biol. Evolut. 30, 752-760. doi: $10.1093 / \mathrm{molbev} / \mathrm{mss} 327$

Mohr, A., and Raman, S. (2013). Lessons from first generation biofuels and implications for the sustainability appraisal of second generation biofuels. Energ. Policy 63, 114-122. doi: 10.1016/j.enpol.2013.08.033

Monteiro, C. M., Castro, P. M. L. and Malcata, F. X. (2011). Microalga-mediated bioremediation of heavy metal-contaminated surface waters, biomanagement of metal-contaminated soils. Environ. Pollut. 20, 365-385. doi: 10.1007/978-94007-1914-9_16

Moosavi, S. G., and Seghatoleslami, M. J. (2013). Phytoremediation: a review. Adv. Agri. Biol. 1, 5-11. Available online at: http://www.pscipub.com/Journals/ Data/JList/Advance\%20in\%20Agriculture\%20and\%20Biology/2013/Volume\% 201/Issue\%201/2.pdf

Mueller-Cajar, O., Stotz, M., and Bracher, A. (2014). Maintaining photosynthetic $\mathrm{CO}_{2}$ fixation via protein remodelling: the rubisco activases. Photosynth. Res. 119, 191-201. doi: 10.1007/s11120-013-9819-0

Mühlroth, A., Li, K., Røkke, G., Winge, P., Olsen, Y., Hohmann-Marriott, M. F., and Bones, A. M. (2013). Pathways of lipid metabolism in marine algae, coexpression network, bottlenecks and candidate genes for Enhanced Production of EPA and DHA in species of chromista. Marine drugs 11, 4662-4697. doi: $10.3390 / \mathrm{md} 11114662$

Mülhaupt, R. (2013). Green polymer chemistry and bio-based plastics: dreams and reality. Macromol. Chem. Phys. 214, 159-174. doi: 10.1002/macp.201200439

Murchie, E. H., and Niyogi, K. K. (2011). Manipulation of photoprotection to improve plant photosynthesis. Plant Physiol. 155, 86-92. doi: 10.1104/pp.110.168831

Naik, S. N., Goud, V. V., Rout, P. K. and Dalai, A. K. (2010). Production of first and second generation biofuels: a comprehensive review. Renew. Sust. Energ. Rev. 14, 578-597. doi: 10.1016/j.rser.2009.10.003

Nair, P. K. R. (2014). Grand challenges in agroecology and land use systems. Front. Environ. Sci. 1, 1-4. doi: 10.3389/fenvs.2014.00001

Nascimento, I. A., Marques, S. S., Cabanelas, I. T. D., Pereira, S. A., Druzian, J. I., de Souza, C. O., et al. (2013). Screening microalgae strains for biodiesel production: lipid productivity and estimation of fuel quality based on fatty acids profiles as selective criteria. Bioenerg. Res. 6, 1-13. doi: 10.1007/s12155-0129222-2

Nazeeruddin, M. K., Kay, A., Rodicio, I., Humphry-Baker, R., Müller, E., Liska, P., et al. (1993). Conversion of light to electricity by cis-X2bis (2, 2'-bipyridyl-4 $4^{\prime}$-dicarboxylate) ruthenium (II) charge-transfer sensitizers $\left(\mathrm{X}=\mathrm{Cl}^{-}, \mathrm{Br}^{-}, \mathrm{I}^{-}\right.$, $\mathrm{CN}^{-}$, and $\mathrm{SCN}^{-}$) on nanocrystalline titanium dioxide electrodes. J. Am. Chem. Soc. 115, 6382-6390. doi: 10.1021/ja00067a063

Nelson, M., Allen, J., Ailing, A., Dempster, W. F., and Silverstone, S. (2003). Earth applications of closed ecological systems: relevance to the development of sustainability in our global biosphere. Adv. Space Res. 31, 1649-1655. doi: 10.1016/S0273-1177(03)80011-X

Olguín, E. J. (2003). Phycoremediation: key issues for cost-effective nutrient removal processes. Biotechnol. Adv. 22, 81-91. doi: 10.1016/S07349750(03)00130-7

Olguín, E. J. (2012). Dual purpose microalgae-bacteria-based systems that treat wastewater and produce biodiesel and chemical products within a biorefinery. Biotechnol. Adv. 30, 1031-1046. doi: 10.1016/j.biotechadv.2012.05.001

Olguín, E. J., Galicia, S., Mercado, G. and Perez, T. (2003). Annual productivity of Spirulina (Arthrospira) and nutrient removal in a pig wastewater recycle process under tropical conditions. J. Appl. Phycol. 15, 249-257. doi: 10.1023/A:1023856702544
Olsson-Francis, K., and Cockell, C. S. (2010). Experimental methods for studying microbial survival in extraterrestrial environments. J. Microbiol. Methods 80, 1-13. doi: 10.1016/j.mimet.2009.10.004

Omori, K., Watanabe, S., Endo, M., Takeuchi, T., and Oguchi, M. (2001) Development of an airtight recirculating zooplankton culture device for closed ecological recirculating aquaculture system (CERAS). J. Space Technol. Sci. Pub. Jap. Rocket Soc.17, 11-17. doi: 10.1016/j.actaastro.2005.06.001

Onofri, S., de la Torre, R., de Vera, J. P., Ott, S., Zucconi, L., Selbmann, L., and Horneck, G. (2012). Survival of rock-colonizing organisms after 1.5 years in outer space. Astrobiology 12, 508-516. doi: 10.1089/ast.2011.0736

Ort, D. R., Zhu, X., and Melis, A. (2011). Optimizing antenna size to maximize photosynthetic efficiency. Plant Physiol. 155, 9-85. doi: 10.1104/pp.110.165886

Oswald, W. J. and Golueke, C. G. (1960). Biological transformation of solar energy. Adv. Appl. Microbiol. 2, 223-262.

Pahl, S. L., Lee, A. K., Kalaitzidis, T., Ashman, P. J., Sathe, S. and Lewis, D. M. (2013). Harvesting, thickening and dewatering microalgae biomass. Algae Biofuels Energ. Dev. Appl. Phycol. 5, 165-185. doi: 10.1007/978-94-007-5479-9_10

Paradiso, R., De Micco, V., Buonomo, R., Aronne, G., Barbieri, G., and De Pascale, S. (2014). Soilless cultivation of soybean for bioregenerative life-support systems: a literature review and the experience of the MELiSSA Project-food characterisation Phase I. Plant Biol. 16, 69-78. doi: 10.1111/plb.12056

Park, J. M., Oh, B. R., Seo, J. W., Hong, W. K., Yu, A., Sohn, J. H. and Kim, C. H. (2013). Efficient production of ethanol from empty palm fruit bunch fibers by fed-batch simultaneous saccharification and fermentation using Saccharomyces cerevisiae. Appl. Biochem. Biotechnol. 170, 1807-1814. doi: 10.1007/s12010-0130314-Z

Parry, M. A., Andralojc, P. J., Scales, J. C., Salvucci, M. E., Carmo-Silva, A. E., and Whitney, S. M. (2013). Rubisco activity and regulation as targets for crop improvement. J. Exp. Bot. 64, 717-730. doi: 10.1093/jxb/ers336

Page, L. E., Liberton, M., and Pakrasi, H. B. (2012). Reduction of photoautotrophic productivity in the cyanobacterium Synechocystis sp. strain PCC 6803 by phycobilisome antenna truncation. Appl. Environ. Microbiol. 78, 6349-6351. doi: 10.1128/AEM.00499-12

Passell, H., Dhaliwal, H., Reno, M., Wu, B., Amotz, A. B., Ivry, E., et al. (2013) Algae biodiesel life cycle assessment using commercial data. J. Environ. Manag. 129, 103-111. doi: 10.1016/j.jenvman.2013.06.055

Patil, P. D., Gude, V. G., Mannarswamy, A., Cooke, P., Nirmalakhandan, N., Lammers, P. and Deng, S. (2012). Comparison of direct transesterification of algal biomass under supercritical methanol and microwave irradiation conditions. Fuel 97, 822-831. doi: 10.1016/j.fuel.2012.02.037

Patil, P. D., Gude, V. G., Mannarswamy, A., Deng, S., Cooke, P., Munson-McGee, S., et al. (2011). Optimization of direct conversion of wet algae to biodiesel under supercritical methanol conditions. Bioresour. Technol. 102, 118-122. doi: 10.1016/j.biortech.2010.06.031

Paul, A. L., Wheeler, R. M., Levine, H. G., and Ferl, R. J. (2013). Fundamental plant biology enabled by The Space Shuttle. Am. J. Bot. 100, 226-234. doi: 10.3732/ajb. 1200338

Paz-Alberto, A. M., and Sigua, G. C. (2013). Phytoremediation: a green technology to remove environmental pollutants. Am. J. Climate Change 2, 71-86. doi: 10.4236/ajcc.2013.21008

Peterhansel, C., Blume, C., and Offermann, S. (2013). Photorespiratory bypasses: how can they work? J. Exp. Bot. 64, 709-715. doi: 10.1093/jxb/ers247

Peterhansel, C., Horst, I., Niessen, M., Blume, C., Kebeish, R., Kürkcüoglu, S., et al. (2010). Photorespiration. Arabidopsis Book 8:e0130. doi: 10.1199/tab.0130

Pittman, J. K. (2011). The potential of sustainable algal biofuel production using wastewater resources. Bioresour. Technol. 102, 17-25. doi: 10.1016/j.biortech.2010.06.035

Plumeré, N. (2012). Single molecules: a protein in the spotlight. Nat. Nanotechnol. 7, 616-617. doi: 10.1038/nnano.2012.175

Plumeré, N. (2013). Interferences from oxygen reduction reactions in bioelectroanalytical measurements: the case study of nitrate and nitrite biosensors. Anal. Bioanal. Chem. 405, 3731-3738. doi: 10.1007/s00216-013-6827-z

Plumeré, N., Campbell, W. H., and Campbell, E. R. (2012a). Systems and Methods for Enzymatic Oxygen Removal. The Nitrate Elimination. Co., Inc. US Patent App. 13/400,974, 2012.

Plumeré, N., Henig, J. and Campbell, W. H. (2012b). Enzyme-Catalyzed $\mathrm{O}_{2}$ removal system for electrochemical analysis under ambient air: application in an amperometric nitrate biosensor. Anal. Chem. 84, 2141-2146. doi: $10.1021 /$ ac2020883 
Pohl, P., and Schimmack, W. (2006). Adsorption of Radionuclides $\left({ }^{134} \mathrm{Cs},{ }^{85} \mathrm{Sr}\right.$, ${ }^{226} \mathrm{Ra},{ }^{241} \mathrm{Am}$ ) by Extracted Biomasses of cyanobacteria (Nostoc carneum, $\mathrm{N}$. insulare, Oscillatoria geminata and Spirulina laxis-Sima) and Phaeophyceae (Laminaria digitata and L. japonica; Waste Products from Alginate Production) at Different pH. J. Appl. Phycol. 18, 135-143. doi: 10.1007/s10811-006-9084-0

Price, G. D., Pengelly, J. J., Forster, B., Du, J., Whitney, S. M., von Caemmerer, S., et al. (2013). The cyanobacterial CCM as a source of genes for improving photosynthetic $\mathrm{CO}_{2}$ fixation in crop species. J. Exp. Bot. 64, 753-768. doi: 10.1093/ jxb/ers 257

Rabbow, E., Rettberg, P., Barczyk, S., Bohmeier, M., Parpart, A., Panitz, C., and Reitz, G. (2012). EXPOSE-E: an ESA astrobiology mission 1.5 years in space. Astrobiology 12, 374-386. doi: 10.1089/ast.2011.0760

Raines, C. A. (2011). Increasing photosynthetic carbon assimilation in C3 plants to improve crop yield: current and future strategies. Plant Physiol. 155, 36-42. doi: 10.1104/pp.110.168559

Rathore, D., Pant, D., and Singh, A. (2013). "A comparison of life cycle assessment studies of different biofuels," in Life Cycle Assessment of Renewable Energy Sources, eds A. Singh, D. Pant, and S. I. Olsen (London: Springer), 269-290. doi: 10.1007/978-1-4471-5364-1_12

Ravi, M., De, S. L., Azharuddin, S., and Paul, S. F. (2010). The beneficial effects of Spirulina focusing on its immunomodulatory and antioxidant properties. Nutr. Dietary Suppl. 2, 73-83. doi: 10.2147/NDS.S9838

Rawat, I., Kumar, R. R., Mutanda, T. and Bux, F. (2011). Dual role of microalgae: phycoremediation of domestic wastewater and biomass production for sustainable biofuels production. Appl. Energ. 88, 3411-3424. doi: 10.1016/j.apenergy.2010.11.025

Rawat, I., Kumar, R. R., Mutanda, T., and Bux, F. (2012). Biodiesel from algae: a critical evaluation from laboratory to large-scale production. Appl. Energ. 103, 444-467. doi: 10.1016/j.apenergy.2012.10.004

Rawat, I., Bhola, V., Kumar, R. R. and Bux, F. (2013). Improving the feasibility of producing biofuels from microalgae using wastewater. Enviro. Technol. 34, 1765-1775. doi: 10.1080/09593330.2013.826287

Rea, G., Polticelli, F., Antonacci, A., Scognamiglio, V., Katiyar, P., Kulkarni, S. A., et al. (2009). Structure-based design of novel Chlamydomonas reinhardtii D1-D2 photosynthetic proteins for herbicide monitoring. Protein Sci. 18, 2139-2151. doi: 10.1002/pro.228

Reddy, H. K., Muppaneni, T., Patil, P. D., Ponnusamy, S., Cooke, P., Schaub, T., et al. (2014). Direct conversion of wet algae to crude biodiesel under supercritical ethanol conditions. Fuel 115, 720-726. doi: 10.1016/j.fuel.2013.07.090

Reece, S. Y., Hamel, J. A., Sung, K., Jarvi, T. D., Esswein, A. J., Pijpers, J. J. H. et al. (2011). Wireless solar water splitting using silicon-based semiconductors and earth-abundant catalysts. Science 334, 645-648. doi: 10.1126/science.1209816

Reynolds, M., Bonnett, D., Chapman, S. C., Furbank, R. T., Manès, Y., Mather, D. E., et al. (2011). Raising yield potential of wheat. I. Overview of a consortium approach and breeding strategies. J. Exp. Bot. 62, 439-452. doi: $10.1093 /$ jxb/erq311

Richards, R. G. and Mullins, B. J. (2013). Using microalgae for combined lipid production and heavy metal removal from leachate. Ecol. Modell. 249, 59-67. doi: 10.1016/j.ecolmodel.2012.07.004

Rivasseau, C., Farhi, E., Atteia, A., Couté, A., Gromova, M., Saint Cyr, D. D. G.,. and Bligny, R. (2013). An extremely radioresistant green eukaryote for radionuclide bio-decontamination in the nuclear industry. Energ. Environ. Sci. 6, 1230-1239. doi: 10.1039/C2EE23129H

Saei, A. A., Omidi, A. A., and Barzegari, A. (2013). Screening and genetic manipulation of green organisms for establishment of biological life support systems in space. Bioeng. Bugs 4, 65-71. doi: 10.4161/bioe.22286

Salih, F. M. (2011). Microalgae tolerance to high concentrations of carbon dioxide: a review. J. Environ. Prot. 2, 648-654. doi: 10.4236/jep.2011.25074

Salisbury, F. B., and Clark, M. A. (1995). Choosing plants to be grown in a Controlled Environment Life Support System (CELSS) based upon attractive vegetarian diets. Life Support Biosph. Sci. Int. J. Earth Space 2, 169-179.

Saunders, R. J., Paul, N. A., Hu, Y., and de Nys, R. (2012). Sustainable sources of biomass for bioremediation of heavy metals in waste water derived from coal-fired power generation. PLoS ONE 7:e36470. doi: 10.1371/journal.pone. 0036470

Scholz, M., Hoshino, T., Johnson, D., Riley, M. R., and Cuello, J. (2011). Flocculation of wall-deficient cells of Chlamydomonas reinhardtii mutant cw15 by calcium and methanol. Biomass Bioenerg. 35, 4835-4840. doi: 10.1016/j.biombioe.2011.08.020
Scognamiglio, V., Pezzotti, G., Pezzotti, I., Cano, J., Buonasera, K., Giannini, D., et al. (2009). Biosensors for effective environmental and agrifood protection and commercialization: from research to market. Microchimica Acta. 170, 215-225. doi: 10.1007/s00604-010-0313-5

Scognamiglio, V., Stano, P., Polticelli, F., Antonacci, A., Lambreva, M. D., Pochetti, G., et al. (2013). Design and biophysical characterization of atrazine-sensing peptides mimicking the Chlamydomonas reinhardtii plastoquinone binding niche. Phys. Chem. Chem. Phys. 15, 13108-13115. doi: 10.1039/C3CP51955D

Scott, S. A., Davey, M. P., Dennis, J. S., Horst, I., Howe, C. J., Lea-Smith, D. J., et al. (2010). Biodiesel from algae: challenges and prospects. Curr. Opin. Biotechnol. 21, 277-286. doi: 10.1016/j.copbio.2010.03.005

Şener, M., Strümpfer, J., Hsin, J., Chandler, D., Scheuring, S., Hunter, C. N., et al. (2011). Förster energy transfer theory as reflected in the structures of photosynthetic light-harvesting systems. Chem. Phys. Chem. 12, 518-531. doi: 10.1002/cphc.201000944

Seufferheld, M. J., and Curzi, M. J. (2010). Recent discoveries on the roles of polyphosphates in plants. Plant Mol. Biol. Report. 28, 549-559. doi: $10.1007 /$ s11105-010-0187-z

Shurin, J. B., Abbott, R. L., Deal, M. S., Kwan, G. T., Litchman, E., McBride, R. C., et al. (2013). Industrial-strength ecology: trade-offs and opportunities in algal biofuel production. Ecol. Lett. 16, 1393-1404. doi: 10.1111/ele.12176

Singh, A. and Olsen, S. I. (2012). "Key issues in life cycle assessment of biofuels," in Sustainable Bioenergy and Bioproducts Green Energy and Technology, eds K. Gopalakrishnan, J. van Leeuwen, (Hans), and R. C. Brown, (Springer). ISBN 978-1-4471-2324-8.

Singh, A., Nigam, P. S. and Murphy, J. D. (2011a). Renewable fuels from algae: an answer to debatable land based fuels. Bioresour. Technol. 102, 10-16. doi: 10.1016/j.biortech.2010.06.032

Singh, A., Nigam, P. S. and Murphy, J. D. (2011b). Mechanism and challenges in commercialisation of algal biofuels. Bioresour. Technol. 102, 26-34. doi: 10.1016/j.biortech.2010.06.057

Singh, H., Fernandes, T., and Apte, S. K. (2010). Unusual radioresistance of nitrogen-fixing cultures of Anabaena strains. J. Biosci. 35, 427-434. doi: 10.1007/s12038-010-0048-9

Singh, J., and Mittal, S. K. (2012). Chlorella sp. based biosensor for selective determination of mercury in presence of silver ions. Sens. Actuators. B Chem. 165, 48-52. doi: 10.1016/j.snb.2012.02.009

Singh, N. K. and Patel, D. B. (2012). Microalgae for bioremediation of distillery effluent, farming for food and water security. Sust. Agricult. Rev. 10, 83-109. doi: 10.1007/978-94-007-4500-1_4

Sivakumar, G., Xu, J., Thompson, R. W., Yang, Y., Randol-Smith, P., and Weathers, P. J. (2012). Integrated green algal technology for bioremediation and biofuel. Bioresour. Technol. 107, 1-9. doi: 10.1016/j.biortech.2011.12.091

Slade, R., and Bauen, A. (2013). Micro-algae cultivation for biofuels: cost, energy balance, environmental impacts and future prospects. Biomass Bioenerg. 53, 29-38. doi: 10.1016/j.biombioe.2012.12.019

Slewinski, T. L. (2013). Using evolution as a guide to engineer Kranz-type C4 photosynthesis. Front. Plant Sci. 4:212. doi: 10.3389/fpls.2013.00212

Slewinski, T. L., Anderson, A. A., Zhang, C., and Turgeon, R. (2012). Scarecrow plays a role in establishing Kranz anatomy in maize leaves. Plant Cell Physiol. 53, 2030-2037. doi: 10.1093/pcp/pcs147

Soh, L., Curry, J., Beckman, E., and Zimmerman, J. (2014). Effect of system conditions for biodiesel production via transesterification using carbon dioxidemethanol mixtures in the presence of a heterogeneous catalyst. ACS Sust. Chem. Engg. 2, 387-395. doi: 10.1021/sc400349g

Song, Q., Zhang, G., and Zhu, X.-G. (2013). Optimal crop canopy architecture to maximise canopy photosynthetic $\mathrm{CO}_{2}$ uptake under elevated $\mathrm{CO}_{2}$ - a theoretical study using a mechanistic model of canopy photosynthesis. Funct. Plant Biol. 40, 109-124. doi: 10.1071/FP12056

Sotiroudis, T. G., and Sotiroudis, G. T. (2013). Health aspects of Spirulina (Arthrospira) microalga food supplement. J. Serbian Chem. Soc. 78, 395-406. doi: $10.2298 /$ jsc121020152s

Spinner, N. S., Vega, J. A. and Mustain, W. E. (2011). Recent progress in the electrochemical conversion and utilization of CO2. Catal. Sci. Technol. 2, 19. doi: $10.1039 / \mathrm{clcy} 00314 \mathrm{c}$

Swainsbury, D. J., Friebe, V. M., Frese, R. N., and Jones, M. R. (2014). Evaluation of a biohybrid photoelectrochemical cell employing the purple bacterial reaction centre as a biosensor for herbicides. Biosens. Bioelectron. 58, 172-178. doi: 10.1016/j.bios.2014.02.050 
Takeuchi, T. (1997). Study on the development of closed ecological recirculating aquaculture system (CERAS) I. CELSS J. 10, 1-4.

Takeuchi, T., and Endo, M. (2004). Recent advances in closed recirculating aquaculture systems. Eco-Engineering 16, 15-20.

Tepfer, D., Zalar, A., and Leach, S. (2012). Survival of plant seeds, their UV screens, and nptII DNA for 18 months outside the International Space Station. Astrobiology 12, 517-528. doi: 10.1089/ast.2011.0744

Tikhomirov, A. A., Ushakova, S. A., Kovaleva, N. P., Lamaze, B., Lobo, M., and Lasseur, C. (2007). Biological life support systems for a Mars mission planetary base: problems and prospects. Adv. Space Res. 40, 1741-1745. doi: 10.1016/j.asr.2006.11.009

Tolley, B. J., Sage, T. L., Langdale, J. A., and Hibberd, J. M. (2012). Individual maize chromosomes in the $\mathrm{C} 3$ plant oat can increase bundle sheath cell size and vein density. Plant Physiol. 159, 1418-1427. doi: 10.1104/pp.112.200584

Uggetti, E., Sialve, B., Trably, E., and Steyer, J. P. (in press). Integrating microalgae production with anaerobic digestion: a biorefinery approach. Biofuels Bioprod. Bior. doi: 10.1002/bbb.1469/abstract

Van Den Hende, S., Vervaeren, H., and Boon, N. (2012). Flue gas compounds and microalgae: (bio-)chemical interactions leading to biotechnological opportunities. Biotechnol. Adv. 30, 1405-1424. doi: 10.1016/j.biotechadv.2012.02.015

van Kooten, G. C. (2013). Climate Change, Climate Science and Economics. Prospects for an Alternative Energy Future (Dordrecht: Springer), XXIII, 466. doi: 10.1007/ 978-94-007-4988-7

van Bellen, J. B. (2009). Why microalgal biofuels won't save the internal combustion machine. Biofuels Bioprod. Bior. 4, 41-52. doi: 10.1002/bbb

Vance, C. P., Uhde-Stone, C., and Allan, D. L. (2003). Phosphorous acquisition and use: critical adaptations by plants for securing a nonrenewable resource. New Phytol. 157, 432-447. doi: 10.1046/j.1469-8137.2003.00695.x

Vandamme, D., Foubert, I. and Muylaert, K. (2013). Flocculation as a lowcost method for harvesting microalgae for bulk biomass production. Trends Biotechnol. 31, 233-239. doi: 10.1016/j.tibtech.2012.12.005

Vanhavere, F., Genicot, J. L., O'Sullivan, D., Zhou, D., Spurný, F., Jadrnícková, I., and Yukihara, E. G. (2008). DOsimetry of BIological EXperiments in SPace (DOBIES) with luminescence (OSL and TL) and track etch detectors. Radiat. Meas. 43, 694-697. doi: 10.1016/j.radmeas.2007.12.002

Vanthoor-Koopmans, M., Wijffels, R. H., Barbosa, M. J. and Eppink, M. H. (2012). Biorefinery of microalgae for food and fuel. Bioresour. Technol. 135, 142-149. doi: 10.1016/j.biortech.2012.10.135

von Caemmerer, S., Quick, W. P., and Furbank, R. T. (2012). The development of C4 rice: current progress and future challenges. Science 336, 1671. doi: 10.1126/science. 1220177

Haehnel, W., and Hochheimer, H. J. (1979). On the current generated by a galvanic cell driven by photosynthetic electron transport. Bioelectrochem. Bioenerg. 6, 563-574. doi: 10.1016/0302-4598(79)80025-2

Wang, B., Li, Y., Wu, N. and Lan C.Q. (2008). $\mathrm{CO}_{2}$ bio-mitigation using microalgae. Appl. Microbiol. Biotechnol. 79, 707-718. doi: 10.1007/s00253-008-1518-y

Wang, G., Liu, Y., Li, G., Hu, C., Zhang, D., and Li, X. (2007). A simple closed aquatic ecosystem (CAES) for space. Adv. Space Res. 41, 684-690. doi: 10.1016/j.asr.2007.09.020

Wang, L., Min, M., Li, Y., Chen, P., Chen, Y., Liu, Y., et al. (2010). Cultivation of green algae Chlorella $s p$. in different wastewaters from municipal wastewater treatment plant. Appl. Biochem. Biotechnol. 162, 1174-1186. doi: 10.1007/s12010-009-8866-7

Wang, L., Peterson, R. B., and Brutnell, T. P. (2011). Regulatory mechanisms underlying C4 photosynthesis. New Phytol. 190, 9-20. doi: 10.1111/j.14698137.2011.03649.x

Wang, P., Kelly, S., Fouracre, J. P., and Langdale, J. A. (2013a). Genome-wide transcript analysis of early maize leaf development reveals gene cohorts associated with the differentiation of C4 Kranz anatomy. Plant J. 75, 656-670. doi: $10.1111 /$ tpj.12229

Wang, P., Fouracre, J., Kelly, S., Karki, S., Gowik, U., Aubry, S., et al. (2013b). Evolution of GOLDEN2-LIKE gene function in C3 and C4 plants. Planta 237, 481-495. doi: 10.1007/s00425-012-1754-3

Wang, Y., and Li, J. (2008) Molecular basis of plant architecture. Annu. Rev. Plant Biol. 59, 253-279. doi: 10.1146/annurev.arplant.59.032607.092902

Wen, M., Bond-Watts, B. B., and Chang, M. C. (2013). Production of advanced biofuels in engineered E. coli. Curr. Opin. Chem. Biol. 17, 472-479. doi: 10.1016/j.cbpa.2013.03.034
Whitney, S. M., Houtz, R. L., and Alonso, H. (2011a). Advancing our understanding and capacity to engineer nature's $\mathrm{CO}_{2}$-sequestering enzyme, Rubisco. Plant Physiol. 155, 27-35. doi: 10.1104/pp.110.164814

Whitney, S. M., Kane, H. J., Houtz, R. L., and Sharwood, R. E. (2009). Rubisco oligomers composed of linked small and large subunits assemble in tobacco plastids and have higher affinities for $\mathrm{CO}_{2}$ and $\mathrm{O}_{2}$. Plant Physiol. 149, 1887-1895. doi: 10.1104/pp.109.135210

Whitney, S. M., Sharwood, R. E., Orr, D., White, S. J., Alonso, H., and Galmés, J. (2011b). Isoleucine 309 acts as a C4 catalytic switch that increases ribulose-1,5-bisphosphate carboxylase/oxygenase (Rubisco) carboxylation rate in Flaveria. Proc. Natl. Acad. Sci. U.S.A. 108, 14688-14693. doi: 10.1073/pnas. 1109503108

Willscher, S., Mirgorodsky, D., Jablonski, L., Ollivier, D., Merten, D., Büchel, G., and Werner, P. (2013). Field scale phytoremediation experiments on a heavy metal and uranium contaminated site, and further utilization of the plant residues. Hydrometallurgy 131-132, January 2013, 46-53. doi: 10.1016/j.hydromet.2012.08.012

Yehezkeli, O., Tel-Vered, R., Wasserman, J., Trifonov, A., and Michaeli, D., Nechushtai, R. et al. (2012). Integrated photosystem II-based photobioelectrochemical cells. Nat. Commun. 3, 742. doi: 10.1038/ncomms1741

Zarzycki, J., Axen, S. D., Kinney, J. N., and Kerfeld, C. A. (2013). Cyanobacterialbased approaches to improving photosynthesis in plants. J. Exp. Bot. 64, 787-798. doi: 10.1093/jxb/ers294

Zeng, Y., Zhao, S., Yang, S. and Ding, S. Y. (2014), Lignin plays a negative role in the biochemical process for producing lignocellulosic biofuels. Curr. Opin. Biotechnol. 27, 38-45. doi: 10.1016/j.copbio.2013. 09.008

Zhao, Y., Swierk, J. R., Megiatto, J. D., Sherman, B., and Youngblood, W. J., Qin, D. et al. (2012). Improving the efficiency of water splitting in dye-sensitized solar cells by using a biomimetic electron transfer mediator. Proceedings of the National Academy of Sciences 109, 15612-15616. doi: 10.1073/pnas.1118 339109

Zheng, Z. P., and Liu, X. H. (2013). Genetic analysis of agronomic traits associated with plant architecture by QTL mapping in maize. Genet. Mol. Res. 12, 1243-1253. doi: 10.4238/2013.April.17.3

Zhou, H., Guo, J., Li, P., Fan, T., Zhang, D., and Ye, J. (2013). Leaf-architectured 3D Hierarchical Artificial Photosynthetic System of Perovskite Titanates Towards CO2 Photoreduction Into Hydrocarbon Fuels. Scientific reports, 3. doi: $10.1038 /$ srep01667

Zhu, G., Kurek, and I., Liu, L. (2010a). "Engineering photosynthetic enzymes involved in $\mathrm{CO}_{2}$-assimilation by gene shuffling," in The Chloroplast: Basics and Application (Advances in Photosynthesis and Respiration), Vol. 31, eds C. A. Rebeiz, C. Benning, H. J. Bohnert, H. Daniell, J. K. Hoober, H. K. Lichtenthaler et al. (Dordrecht: Springer), 307-322.

Zhu, X.-G., Long, S. P., and Ort, D. R. (2010b). Improving photosynthetic efficiency for greater yield. Ann. Rev. Plant Biol. 61, 235-261. doi: 10.1146/annurevarplant-042809-112206

Zhu, X.-G., Song, Q., and Ort, D. R. (2012). Elements of a dynamic systems model of canopy photosynthesis. Curr. Opin. Plant Biol. 15, 237-244. doi: 10.1016/j.pbi.2012.01.010

Conflict of Interest Statement: The authors declare that the research was conducted in the absence of any commercial or financial relationships that could be construed as a potential conflict of interest.

Received: 14 March 2014; accepted: 25 May 2014; published online: 12 June 2014. Citation: Janssen PJD, Lambreva MD, Plumeré N, Bartolucci C, Antonacci A, Buonasera K, Frese RN, Scognamiglio V and Rea G (2014) Photosynthesis at the forefront of a sustainable life. Front. Chem. 2:36. doi: 10.3389/fchem.2014.00036 This article was submitted to Agricultural Biological Chemistry, a section of the journal Frontiers in Chemistry.

Copyright (C) 2014 Janssen, Lambreva, Plumeré, Bartolucci, Antonacci, Buonasera, Frese, Scognamiglio and Rea. This is an open-access article distributed under the terms of the Creative Commons Attribution License (CC BY). The use, distribution or reproduction in other forums is permitted, provided the original author(s) or licensor are credited and that the original publication in this journal is cited, in accordance with accepted academic practice. No use, distribution or reproduction is permitted which does not comply with these terms. 